\title{
A modelling case study of a large-scale cirrus in the tropical tropopause layer
}

\author{
Aurélien Podglajen, Riwal Plougonven, Albert Hertzog, and Bernard Legras \\ Laboratoire de Météorologie Dynamique (LMD), CNRS-UMR8539, Institut Pierre Simon Laplace, École Normale \\ Supérieure, École Polytechnique, Université Pierre et Marie Curie, Paris, France \\ Correspondence to: Aurélien Podglajen (aurelien.podglajen@1md.polytechnique.fr)
}

Received: 17 September 2015 - Published in Atmos. Chem. Phys. Discuss.: 6 November 2015

Revised: 13 February 2016 - Accepted: 28 February 2016 - Published: 23 March 2016

\begin{abstract}
We use the Weather Research and Forecast (WRF) model to simulate a large-scale tropical tropopause layer (TTL) cirrus in order to understand the formation and life cycle of the cloud. This cirrus event has been previously described through satellite observations by Taylor et al. (2011). Comparisons of the simulated and observed cirrus show a fair agreement and validate the reference simulation regarding cloud extension, location and life time. The validated simulation is used to understand the causes of cloud formation. It is shown that several cirrus clouds successively form in the region due to adiabatic cooling and large-scale uplift rather than from convective anvils. The structure of the uplift is tied to the equatorial response (equatorial wave excitation) to a potential vorticity intrusion from the midlatitudes.

Sensitivity tests are then performed to assess the relative importance of the choice of the microphysics parameterization and of the initial and boundary conditions. The initial dynamical conditions (wind and temperature) essentially control the horizontal location and area of the cloud. However, the choice of the microphysics scheme influences the ice water content and the cloud vertical position.

Last, the fair agreement with the observations allows to estimate the cloud impact in the TTL in the simulations. The cirrus clouds have a small but not negligible impact on the radiative budget of the local TTL. However, for this particular case, the cloud radiative heating does not significantly influence the simulated dynamics. This result is due to (1) the lifetime of air parcels in the cloud system, which is too short to significantly influence the dynamics, and (2) the fact that induced vertical motions would be comparable to or smaller than the typical mesoscale motions present. Finally, the simulation also provides an estimate of the vertical redistribution
\end{abstract}

of water by the cloud and the results emphasize the importance in our case of both rehydration and dehydration in the vicinity of the cirrus.

\section{Introduction}

Cirrus are the most frequent type of clouds, covering about 30 to $50 \%$ of the Earth surface (Stubenrauch et al., 2010). From remote-sensing observations, they seem nearly ubiquitous in the tropical tropopause layer (TTL; Wang et al., 1996; Fueglistaler et al., 2009) and radiative transfer calculations suggest that they strongly influence the heat balance of the TTL, potentially influencing its temperature and contributing to tropical upwelling (Corti et al., 2005). Furthermore, TTL cirrus are believed to control the dehydration of air masses and the amount of water vapour that enters the stratosphere (Jensen et al., 1996).

Despite the remarkable attention they have received for the last 20 years, the microphysical processes controlling the formation of TTL cirrus are still largely debated. More precisely, the respective importance of homogenous and heterogeneous nucleation remains unclear, although in situ observations suggest that both are active in the TTL (Jensen et al., 2013; Cziczo et al., 2013). Contrary to the microphysics, the dynamics leading to cirrus seems somehow better understood. The clouds result either from ice detrainment from convective towers or from in situ formation in supersaturated regions created by large- to mesoscale uplifts (Wang and Dessler, 2012). Nevertheless, the role of different waves with different scales in cirrus processes is still discussed, and 
their impacts still require quantification (Kim and Alexander, 2015).

Processes in TTL cirrus have mainly been studied using a Lagrangian framework (parcel or single column models; Jensen and Pfister, 2004) or with idealized mesoscale simulations (e.g. Jensen et al., 2011; Dinh et al., 2012). There have been relatively few studies conducting meso- to large-scale modelling of real-case TTL cirrus. Different reasons may contribute to this: the fact that the typical spatial scale of TTL cirrus can go down to a few metres in the vertical, the many unknowns in the microphysics and the uncertainty regarding how detailed the microphysics modelling needs to be (bin or bulk). Despite these important limitations, simulations using a mesoscale model of tropical cirrus have nonetheless been carried out, but in a climatological perspective, i.e. using a moderate resolution and several months of simulations $(\mathrm{Wu}$ et al., 2012; Evan et al., 2013). Now, mesoscale simulations can also be used for case studies of individual clouds to address issues such as the dynamical causes of cloud formation. Such case studies will contribute to evaluating the realism of the macrophysical characteristics of the simulated cirrus (location, altitude, timing, extent). If these characteristics are successfully modelled, the simulation may serve to explore the cirrus evolution and its impact. Recently, Muhlbauer et al. (2014) used case studies with a mesoscale (cloud resolving) model to explore the sensitivity of different types of cirrus to modifications of the microphysical parameters and to modifications of the initial conditions. However, the mesoscale model tool has mainly been used to study midlatitude cirrus (e.g. Muhlbauer et al., 2015).

In this paper, we use the Advanced Research Weather Research and Forecast (ARW WRF; Skamarock et al., 2008) model to conduct a real-case study of an in situ formed TTL cirrus cloud. The case studied corresponds to a cloud having a very large spatial extent and occurring over the Eastern Pacific. Taylor et al. (2011) pointed out this cloud event and analysed it using satellite observations. In particular, they have shown that the cloud occurred within a large-scale lowtemperature anomaly, which was itself probably related to a potential vorticity (PV) intrusion originating from the midlatitudes. The large-scale in situ formation of this cloud makes it suitable for a case study with a mesoscale model. Indeed, one can hope that the analyses used to force the model contain the necessary dynamical components to drive the cirrus formation, although the Eastern Pacific is a region where analyses may present significant errors due to the sparsity of observations (Podglajen et al., 2014). Finally, the choice of this cloud for the study is also motivated by the possibility to investigate dynamics-radiation interaction, which may have played a role in the cloud evolution for this case (Taylor et al., 2011).

The paper is organized as follows. In Sect. 2, the model set-up and an overview of the cirrus event in the simulations are presented. We show that despite uncertainties and crude assumptions in its microphysical parameterization, the model is able to reproduce the main characteristics of the observed cloud structure. In Sect. 3, we explain that this good agreement between observed and modelled clouds is tied to the well-represented large-scale dynamics. Section 4 illustrates several sensitivity studies and the strong dependence to the choice of the initial and boundary conditions. Finally, Sect. 5 discusses the modelled impact of the cloud in the tropical tropopause layer.

\section{Model and observations}

\subsection{Case description}

The study focuses on a cirrus cloud forming in the tropical Eastern Pacific in late January 2009. This case was highlighted as remarkable for its very large horizontal extent by Taylor et al. (2011), who analysed it using satellite observations. In measurements from the Cloud-Aerosol Lidar with Orthogonal Polarization (CALIOP, Winker et al., 2007), one can identify the large region covered by the cirrus through its intensified backscatter (Fig. 1, top left panel, similar to Fig. 1 of Taylor et al., 2011). In particular, the cloud seems to extend almost continuously over $3000 \mathrm{~km}$ along track, at an altitude between 15 and $16 \mathrm{~km}$. In addition to this considerable spatial extent, Taylor et al. (2011) showed that high clouds were seen on CALIOP tracks during several days (2729 January) and suggested that they could be portions of the same extensive cirrus. The cloud would then extend several thousand kilometres in the zonal direction as well and last a few days.

Regarding the atmospheric flow in the tropical Eastern Pacific region, where the cloud forms, climatological westerlies dominate at upper-tropospheric levels, as part of the Walker circulation. However, they can be strongly modulated at synoptic timescales by PV intrusions from the midlatitudes. This is the case at the time of our simulation, as we will see in Sect. 3.

\subsection{Model description and set-up}

To simulate the cirrus event, we use the WRF mesoscale model (Skamarock et al., 2008). The relevant elements of our reference set-up are described in the following, while the different sensitivity tests that were carried out will be the subject of Sect. 4.

Our spatial domain extends from $18^{\circ} \mathrm{S}$ to $18^{\circ} \mathrm{N}$ and from 148 to $112^{\circ} \mathrm{W}$ (i.e. about $4000 \times 4000 \mathrm{~km}$ ), and the nominal horizontal resolution is $10 \mathrm{~km}$ (i.e. $400 \times 400$ points). The domain was chosen to surround the cloud seen in CALIOP observations in Fig. 1. It is large enough that the development of the cirrus clouds at its centre is not much affected by the boundary conditions, according to trajectory analysis. In the vertical, there are 120 levels extending up to $8 \mathrm{hPa}$, with the last $7 \mathrm{~km}$ taken as a sponge layer to avoid spurious wave reflection. The resulting vertical resolution around 

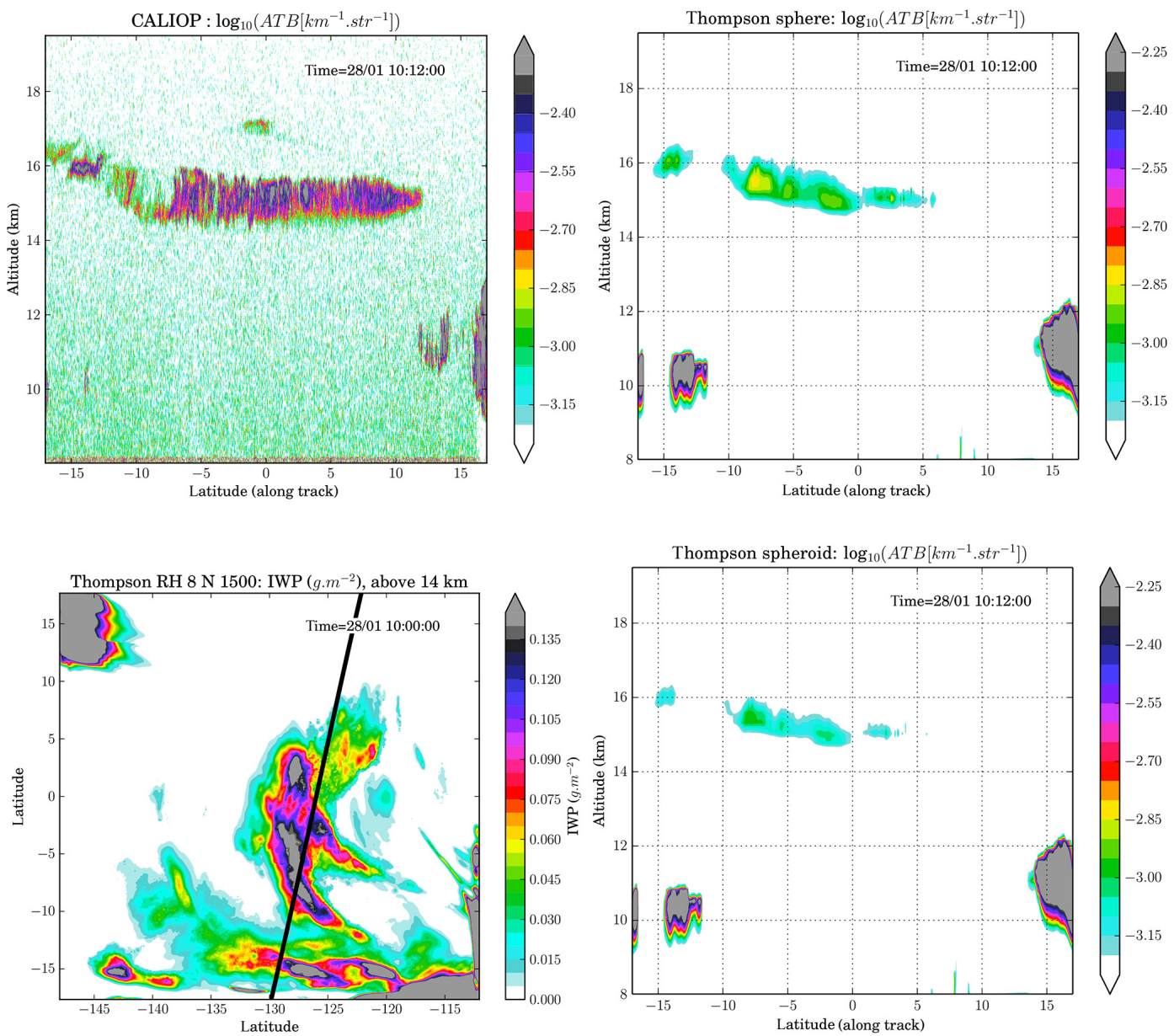

Figure 1. (Top two panels) Decimal logarithm of total attenuated backscatter (ATB) at $532 \mathrm{~nm}$, from (left) CALIOP observations and (right) WRF reference simulation, using default Thompson microphysics and assuming spherical ice crystals. ATB in the simulation assuming non spherical crystals is also shown (bottom right). (Bottom left panel): total ice water path above $14 \mathrm{~km}$ in the reference simulation, at the time of CALIOP passage. The satellite track is highlighted by the black line.

$15 \mathrm{~km}$ is approximately $300 \mathrm{~m}$. The model is initialized on 27 July at 00:00 UTC. Although we performed a 4-day integration for the reference simulation, the paper is focused on the shorter period 27-29 July. One reason is that this time period includes the observations along CALIPSO track shown in Fig. 1. Another reason is that in longer simulations, at the altitudes considered (14-17 km), most of the air that was initially inside the domain has been advected out of it within 2 days or less, thus preventing the analysis with tracers initialized in the initial condition (see Sects. 3 and 5). In addition to this, the first $12 \mathrm{~h}$ of the simulation are regarded as spin-up and not shown. This is conservative: deep convection is very limited in our simulations, so little adjustment to latent heat release is expected, resulting in an effective spin-up time of only a few hours.

In the reference simulation, microphysical processes are treated with the bulk microphysics scheme of Thompson (Thompson et al., 2004, 2008; Thompson and Eidhammer, 2014), which has two moments for the ice class. The ice number concentration is assumed to follow an exponential distribution with respect to the diameter. The massdiameter relationship adopted is $m(D)=\rho_{i} \frac{\Pi}{6} D^{3}$, with $\rho_{i}=$ $890 \mathrm{~kg} \mathrm{~m}^{-3}$ standing for ice density; i.e. the ice crystals are assumed to be spherical. With two moments for ice, differential sedimentation occurs in the scheme with different mass weighted and number weighted terminal fall speeds. The scheme allows for ice supersaturation and includes homogeneous nucleation (Koop et al., 2000) and an empirical treatment that could be considered as heterogeneous nucleation. Here, the heterogeneous ice nuclei are activated once a supersaturation threshold $S_{\text {nuc }}=8 \%$ is reached, and their number $N_{\text {IN }}$ follows the observations of Cooper (1986) above $233 \mathrm{~K}$ and are saturated to their value at $233 \mathrm{~K}$ (i.e. 1500 crystals per litre) below that. These values of $N_{\text {IN }}$ and $S_{\text {nuc }}$ may seem unlikely for heterogeneous ice nuclei concentrations and properties at $15-16 \mathrm{~km}$ in the TTL, although to our knowledge no direct measurements are available for compar- 
ison in this region. We emphasize that, if one can interpret this ice-formation procedure as heterogeneous nucleation, it can also be better thought of as an empirical parameterization of the combined effect of heterogeneous and homogeneous nucleation triggered by resolved and unresolved perturbations inside the $10 \mathrm{~km} \times 10 \mathrm{~km} \times 300 \mathrm{~m}$ grid box. This explains the rather low supersaturation for ice formation that compensates for the fact that the box mean supersaturation is below the local maxima encountered within the grid box. To address the sensitivity to the nucleation-related parameters ( $N_{\mathrm{IN}}$ and $S_{\text {nuc }}$ ), we have performed sensitivity tests that are described in Sect. 4 together with the sensitivity to the microphysics scheme. Moreover, we have also used the microphysical schemes of Morrison et al. (2005, hereafter Morrison) and Hong et al. (2004, hereafter WSM5), which handle nucleation at cold temperature in a similar way as Thompson scheme. Those experiments are also presented in Sect. 4. Our choice of the default Thompson scheme as reference among the many WRF microphysics schemes is a compromise between keeping acceptable computational costs and describing potentially important processes such as differential sedimentation; it is also motivated by the good comparison with observations obtained in this configuration, presented below.

Short- and long-wave radiative heating rates are calculated using the Rapid Radiative Transfer Model G (RRTMG; Iacono et al., 2008). RRTMG is fully coupled to the Thompson microphysics and accounts for the radiative effect of cloud particles through their mass and effective radius. In the radiative calculations, the values of well-mixed greenhouse gas concentrations and of the ozone mixing ratio are taken from the Community Atmosphere Model with Chemistry (CAMchem) outputs, with monthly and latitudinal variations (see WRF user's guide). Finally, the initial and lateral boundary conditions come from the ECMWF operational analysis, which at that time had 91 vertical levels and a T1279 spectral resolution (corresponding to a horizontal resolution of about $\left.0.125^{\circ}\right)$.

\subsection{Model validation against CALIPSO observations}

In order to compare WRF outputs with CALIOP observations, we use the lidar simulator from the Cloud Feedback Model Intercomparison Project Observation Simulator Package (COSP; see Chepfer et al. (2008) for a description). Light scattering by ice particles is a complicated problem and in theory depends on the size distribution, shape and orientation of ice crystals on top of their concentration. In the COSP lidar simulator, only the dependences of the lidar signal to ice concentration and ice crystal effective radius are retained. Those two are calculated consistently between the different microphysical parameterization used and the lidar simulator.

For the comparison, we will mainly use the observed and simulated total attenuated backscatter (ATB) at $532 \mathrm{~nm}$ without any normalization. The ATB is an almost direct measurement, and the absence of normalization is appropriate as long as we are interested in one specific and limited altitude range. Figure 1 shows the along-track profiles of the ATB observed by CALIOP (top left) and simulated by WRFCOSP (top right) for the reference case on 28 January 2009. Despite the crude microphysical treatment of ice nucleation in the reference Thompson scheme, there is an overall good agreement between observed and simulated cirrus cloud location and extension (quantitative evaluation will be used in Sect. 4 to compare different choices for the simulations). The northern extension of the cloud field appears underestimated along CALIPSO track, but the simulation does show an extension beyond $5^{\circ} \mathrm{N}$ to the east of the track (see Fig. 1).

This agreement qualitatively validates the simulation of the general dynamics which led to cloud formation. However, the model visually seems to underestimate the backscatter by a factor of about 2. Possible reasons are the uncertainties associated with measurement noise (typically about $35-50 \%$ of the measured ATB for our cloud) and approximations and uncertainties in the calculated backscatter from WRF outputs.

Shape assumptions is one source of such uncertainties. Here, the choice of the ATB for comparison implies that the hypothesis about ice crystal shapes are made in the COSP lidar simulator and not in the retrieval. Hence, we do not rely on the lidar ratio chosen in the CALIOP retrieval algorithm, contrary to what would have happened if we had used CALIOP's extinction coefficients for example (Mioche et al., 2010). This allows us to evaluate the sensitivity to shape assumptions directly by varying parameters in COSP. Among the choices available, we have tested for differences between spherical and non-spherical prolate shapes. The results for this experiment are illustrated in Fig. 1 (top right and bottom right panels). The strong difference in amplitude seen between the two panels agrees with results stressed for instance by Cirisan et al. (2014), who showed that changing the assumed aspect ratio of prolate spheroids by $20 \%$ could modify the backscatter by a factor of 2 . For our simulation, the best agreement in the signal amplitude is achieved assuming spherical crystals, which agrees with the shape assumption in the microphysics scheme and with observations of the shape of small TTL ice crystals (McFarquhar et al., 2000; Lawson et al., 2008). At last, beside shape assumptions, the type of ice crystal size distribution assumed also affects the simulated ATB; however, we did not test the sensitivity to this parameter to keep consistency with the microphysical parameterization, which assumes an exponential distribution. In light of the strong unknowns in the measurements and in the comparison procedure, the agreement found between the top left and right panels in Fig. 1 is very encouraging.

Nevertheless, in addition to the "comparison related" uncertainties mentioned above, the disagreement between the observed and simulated backscatter intensities may also be due to an underestimation of the ice water content (IWC). A number of factors could then be involved: inappropriate microphysics, too much diffusion of water vapour in the model, 
Table 1. List of parameterizations and simulations used in this paper.

\begin{tabular}{llll}
\hline Simulation name & Microphysics & Radiation & $\begin{array}{l}\text { Initial and } \\
\text { boundary conditions }\end{array}$ \\
\hline Thompson & Thompson & RRTMG & ECMWF op. an. \\
Thompson-ERAi & Thompson & RRTMG & ERA-Interim \\
Morrison & Morrison & RRTMG & ECMWF op. an. \\
Morrison-ERAi & Morrison & RRTMG & ERA-Interim \\
WSM5 & WSM5 & RRTMG & ECMWF op. an. \\
No heat & Thompson & RRTMG, no cloud & ECMWF op. an. \\
& & radiative heating & \\
\hline
\end{tabular}

Centre for $\mathrm{Med}$

Table 2. Bulk microphysical properties (ice water content, ice crystal number and effective radius, $R_{\text {eff }}$ ) of the simulated cirrus clouds at $15.5 \mathrm{~km}$ on January 28, at 10:00 and values reported from aircraft observations (Lawson et al., 2008).

\begin{tabular}{lcc|lc}
\hline & \multicolumn{2}{c}{ WRF simulation } & \multicolumn{2}{|c}{ Lawson et al. (2008) } \\
\cline { 2 - 5 } & mean & $\sigma$ & mean & $\sigma$ \\
\hline $\begin{array}{l}\text { Ice crystal } \\
\text { number }\left(\mathrm{L}^{-1}\right)\end{array}$ & 85. & 131. & 66. & 31. \\
$\begin{array}{l}R_{\text {eff }} \\
\text { (microns) }\end{array}$ & 10.4 & 1.8 & 8.8 & 2.4 \\
$\begin{array}{l}\text { Ice water } \\
\text { content }\left(\mathrm{mg} \mathrm{m}^{-3}\right)\end{array}$ & 0.10 & 0.17 & 0.06 & 0.1 \\
\hline
\end{tabular}

underestimation of the water vapour content in the initialization or overestimation of the temperature. In fact, it is likely that several of those factors are at play and partly compensate, e.g. underestimation of both water vapour and supersaturation. In the absence of more constraining data, we do not attempt here any tuning of the initial conditions but we will provide some discussion on the sensitivity to those in Sect. 4. Due to the absence of in situ observational data for this case, it is also impossible to precisely evaluate the simulated microphysics. However, as shown in Table 2, we note that the simulated cloud microphysical properties are comparable to in situ observations by Lawson et al. (2008) and within the range of other observations from Krämer et al. (2009); Davis et al. (2010); Jensen et al. (2013).

Finally, one should add that the simulated and analysed temperature fields show significant local departures from one another, up to $3 \mathrm{~K}$ at $16 \mathrm{~km}, 36 \mathrm{~h}$ after initialization, though no systematic bias is noted. Those differences typically correspond to mesoscale structures of $\sim 1000 \mathrm{~km}$ horizontal extent, yet they have small amplitudes $(<0.5 \mathrm{~K})$ in the region with significant IWC. With these differences in absolute temperature, it may be rather surprising that the simulated cloud is so similar to observations. This arises because of the strong constraint provided by the large-scale dynamics leading to the cloud formation. This is the subject of Sect. 3, but first an overview of the cirrus evolution in the simulation is provided in the next subsection.

\subsection{Simulated cirrus evolution}

Figure 2 shows the evolution of the temperature and cirrus field in the simulation, at the potential temperature level $\theta=360 \mathrm{~K}$. On those maps, we see that the correlation between the cloud field and low-temperature anomalies, as observed by Taylor et al. (2011), is reproduced in the WRF simulation. As expected due to the dependence of microphysical processes on relative humidity, which itself depends on temperature, the cloud development closely follows the evolution of low temperatures in the simulation.

The colour points on the figure illustrate individual air parcels positions initialized on 28 January, 10:00, at $\theta=$ $360 \mathrm{~K}$ and at the horizontal position shown on the panel corresponding to this time in Fig. 2. The displacement of those air parcels comes from backward and forward (kinematic) Lagrangian trajectories calculated with the wind field in the simulation. Due to diabatic heating, the potential temperature level of those air parcels obviously changes during the time of the simulation. However, the trajectory calculations show that this change is limited to less than $1 \mathrm{~K}$ during the simulation, which is consistent with the value of diabatic heating rates. Hence the representation of those points on the isentrope $\theta=360 \mathrm{~K}$ does not introduce any qualitative bias.

One conclusion from those trajectories is that although the flow has a stagnation point and weak velocities at the centre of the domain (see the evolution of the blue and black point positions), air parcels nonetheless experience significant variations in temperature, partly due to the westward displacement of the cold-temperature anomaly. Moreover, aside from air parcels near the stagnation region, significant horizontal displacements are found (of the order of $1000 \mathrm{~km}$ per day). Different clouds are always present in the simulation but, due to the temperature variability along the trajectory (which is linked to different mesoscale perturbations), they do not follow air parcels and this limits the in-cloud residence time for each cloud (see also Sect. 5.2).

One last important property of this cloud field is that, despite its "patchy" feature, different clouds appear in the same regions, which suggest some large-scale forcing of the cloud. In the following Sect. 3, the causes of cloud formation in the simulation are examined more precisely.

\section{Dynamical features leading to cloud formation}

\subsection{Cause of ice cloud formation}

Cirrus clouds in the TTL can either form in situ through the cooling of ascending air masses or result from ice lofting from convective clouds (Fueglistaler et al., 2009). For our case, Taylor et al. (2011) argued that the latter was unlikely due to the horizontal extent of the cloud. Furthermore, there was no evidence of deep convection taking place in the region of interest at that time in CALIPSO observations. To 

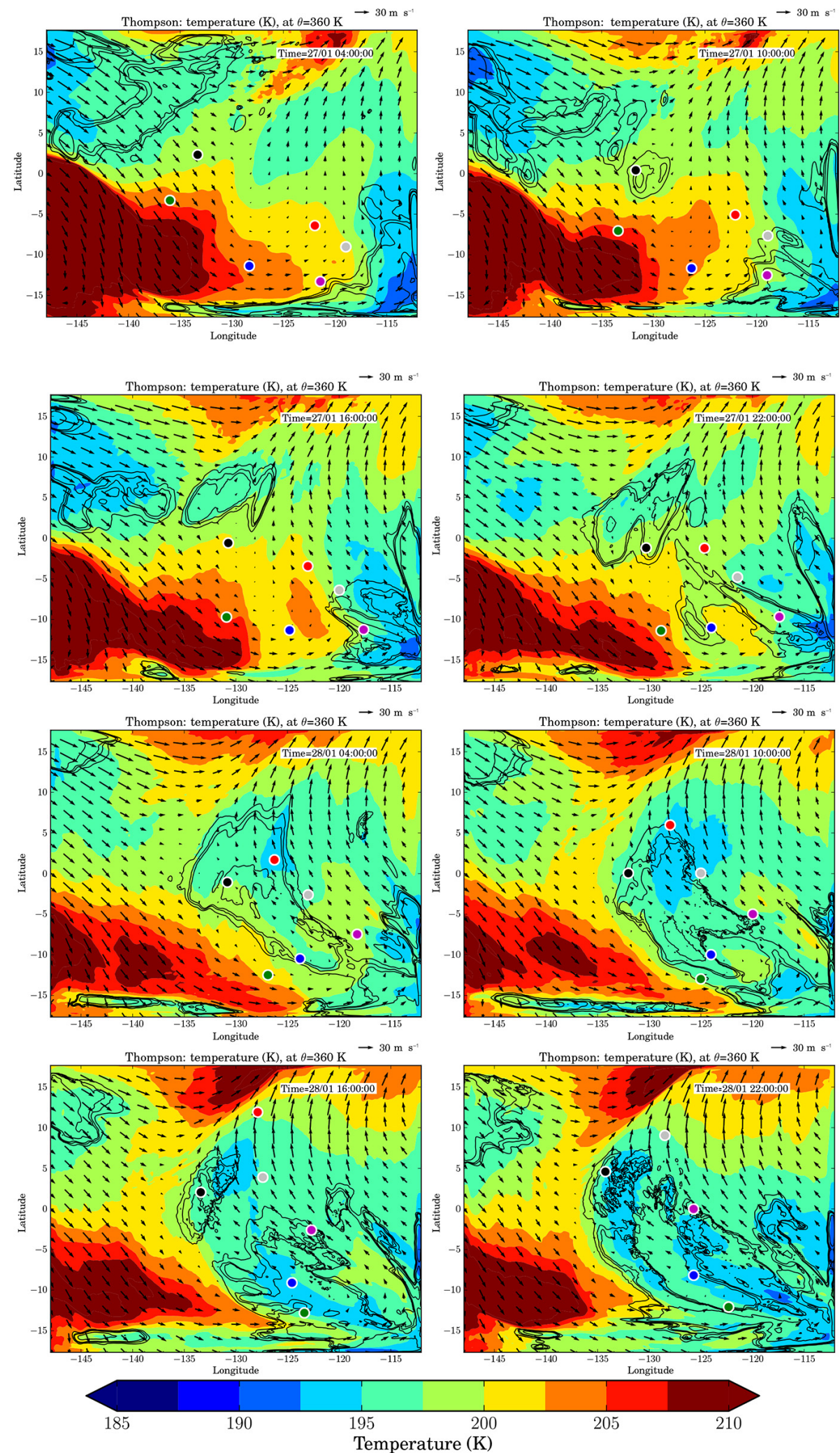

Figure 2. Successive maps of temperature at the potential temperature level $\theta=360 \mathrm{~K}$ for the reference simulation. The black contours correspond to contours of ice water content of $1 \times 10^{-8}, 5 \times 10^{-8}, 1 \times 10^{-8}$ and $5 \times 10^{-8} \mathrm{~kg} \mathrm{~kg}^{-1}$ respectively. They delimit the cirrus. The colour points represent the position of air parcels surrounding the cirrus on 28 January at 10:00 UTC; they were launched (backward and forward) at that date on the isentrope $\theta=360 \mathrm{~K}$, at the horizontal positions shown by the colour points. They follow individual 3-D air-parcel trajectories and illustrate the air displacement in the region. The vectors represent the horizontal winds. 
support their assertion, we have introduced passive tracers in the boundary layer at the beginning of the simulation (27 January 00:00 UTC). None of them had reached the cirrus altitude $(>14 \mathrm{~km})$ at the end of the simulation.

Hence in situ formation prevails here, and it must happen through the cooling of ascending air masses. Using GPS radio-occultation temperature measurements, Taylor et al. (2011) showed that the synoptic situation in the cirrus region was associated with a cold-temperature anomaly in the TTL. The strong link of the cirrus clouds with low-temperature anomalies in the simulation can be seen in Fig. 2, where the cirrus, highlighted by the contours of the IWC, tend to be present in the coldest regions. One naturally thinks of cold-temperature anomalies as associated with strong constant upward vertical velocities because of the cooling associated with adiabatic expansion, which relates air parcels (Lagrangian) cooling rates $\frac{\mathrm{D} T}{\mathrm{D} t}$ and $w$ through

$\left(\frac{\mathrm{D} T}{\mathrm{D} t}\right)_{\text {adiabatic }}=-\frac{g}{C_{\mathrm{p}}} w$,

where $g=9.81 \mathrm{~m} \mathrm{~s}^{-2}$ is the gravitational acceleration and $C_{\mathrm{p}}=1004 \mathrm{~J} \mathrm{~kg}^{-1} \mathrm{~K}^{-1}$ is the thermal capacity of dry air at constant pressure. However, there is no clear correlation between $w$ and the cirrus cloud in most of our simulations (not shown). While this may seem puzzling at first, it simply reflects that the simulated clouds formed in wave-induced negative-temperature anomalies $\Delta T$, which are related to upward vertical displacements $\xi$, i.e. time-integrated Lagrangian vertical velocity, rather than directly to upward velocities. Indeed, in the dry adiabatic limit,

$\Delta T=-\frac{g}{C_{\mathrm{p}}} \xi=-\frac{g}{C_{\mathrm{p}}} \int_{\underline{X}} w(\underline{X}(t), t) \mathrm{d} t$,

where $\int_{X}$ is the integral following $\underline{X}(t)$, the air parcel position. Because of the horizontal velocity, uplift cannot be estimated directly with instantaneous $w$. A more appropriate quantity is the height of an isentropic surface, which is shown for instance for 28 January, 10:00 UTC, in Fig. 3, left panel. There is a good correlation of this height with the cirrus and temperature; however, the height of the isentrope is not computed following an air parcel and does not enable to quantify the uplift created by the dynamics in the simulation.

To quantify this uplift more precisely, we have computed Lagrangian trajectories in the WRF simulation. This also allows to evaluate the upward displacement in the more natural altitude coordinate, which is that of CALIOP observations. The deduced uplift, calculated since the start of the simulation, is shown in Fig. 4, left panel. Part of the figure is intentionally left blank, because the corresponding air was not in the domain at the initial time. The cirrus location is clearly associated with strong vertical uplifts, and the northern limit of the cloud corresponds to a reversal of the sign of the vertical displacement, which becomes negative in the northern part of the domain. To further show that the simulated relative humidity is actually controlled by the vertical displacement field and not directly by the initial conditions, we have also computed a $\Delta \mathrm{RH}$, which is defined as

$$
\begin{aligned}
\Delta \mathrm{RH} & =\frac{q_{\mathrm{vap}}(\underline{X}(t), t)+q_{\text {ice }}(\underline{X}(t), t)}{q_{\mathrm{sat}}(\underline{X}(t), t)} \\
& -\frac{q_{\mathrm{vap}}\left(\underline{X}\left(t_{0}\right), t_{0}\right)+q_{\text {ice }}\left(\underline{X}\left(t_{0}\right), t_{0}\right)}{q_{\mathrm{sat}}\left(\underline{X}\left(t_{0}\right), t_{0}\right)},
\end{aligned}
$$

where $\underline{X}(t)$ indicates that we follow a Lagrangian trajectory, $q_{\text {sat }}$ is the mass saturation mixing ratio with respect to ice, and $q_{\text {vap }}$ and $q_{\text {ice }}$ are the ice and vapour mass mixing ratios. Neglecting sedimentation and diffusion, the numerator of the two terms is the same (Lagrangian conservation of the total water). Hence, this quantity, which is shown in the right panel of Fig. 4, evolves in a Lagrangian manner because of the change of the denominator $q_{\mathrm{sat}}(\underline{X}(t), t)$, which is due to the vertical displacement and the associated adiabatic temperature change. It allows us to distinguish the contribution of the simulation's internal dynamics in driving a relative humidity increase from the initial conditions. The strong correlation of $\Delta \mathrm{RH}$ with the cirrus location (shown by the black contours) confirms that in this case study the simulated cirrus forms because the upward vertical displacement caused an increase in the relative humidity and not because the relative humidity was already high enough in the initial conditions. Still, initial relative humidity, if too dry, can impact the cloud location because the ice formation threshold is not reached, as seen in the south-east part of the domain. Nonetheless, Fig. 4 shows that the dynamically induced vertical displacement exerts a strong control over the cloud structure.

\subsection{Large-scale dynamics}

A large-scale uplift thus explains the formation of the clouds, but the question of the cause of this uplift remains. Taylor et al. (2011) pointed out that the cold-temperature anomaly was most likely related to dynamical features originating in the extratropics. In particular, they showed a map of PV from NCEP reanalysis at $200 \mathrm{hPa}$ (see their Fig. 9), illustrating intrusions of high PV anomalies extending in the region where the cirrus form. A comparable figure for our simulation is displayed in Fig. 3, right panel, which shows the PV at $\theta=360 \mathrm{~K}$. A clear northern hemispheric PV intrusion can be identified in this figure and the large-scale dynamics in the simulation are likely strongly affected by this structure.

This kind of influence from the midlatitudes is common in the Eastern Pacific upper troposphere (Waugh and Polvani, 2000), where the average westerly winds associated with the Walker circulation enable inter-hemispheric interactions. Intruding in tropical regions, the midlatitude signals are expected to excite equatorial modes (Kiladis and Feldstein, 1994). We examined this using fields from the ERA-Interim. Figure 5 shows a Hovmöller diagram of the (left) symmetric 

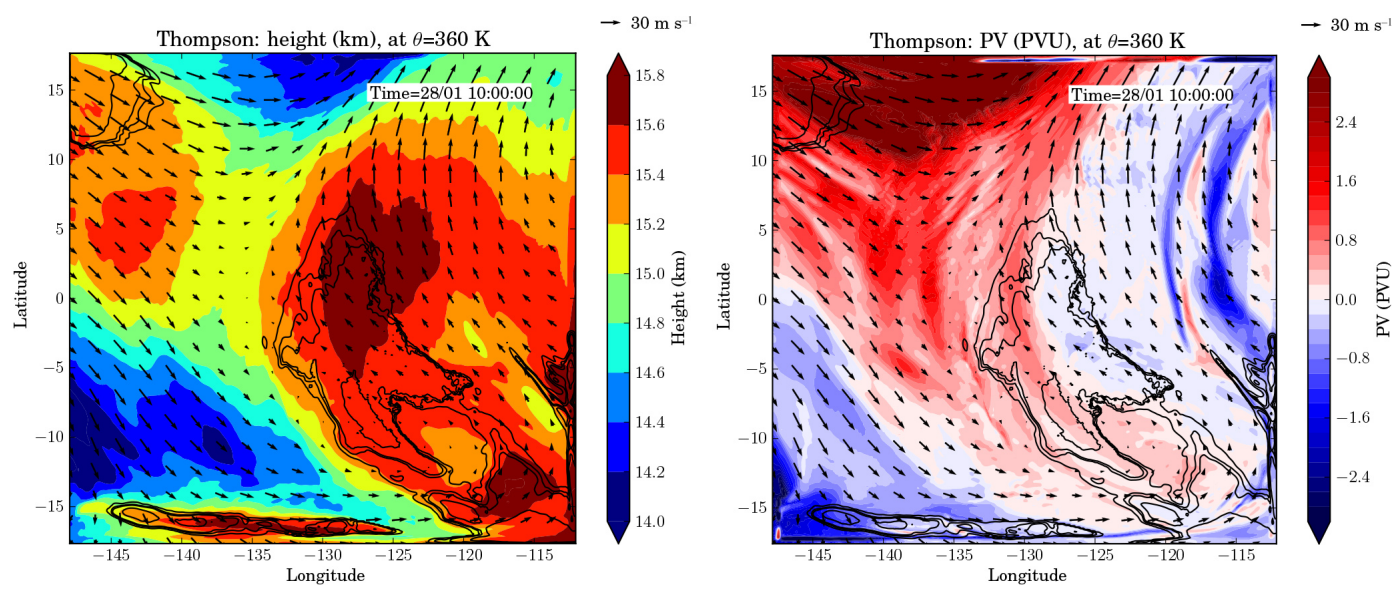

Figure 3. Fields from the reference simulation with Thompson microphysics, on the $360 \mathrm{~K}$ isentrope, showing (left) geopotential height (km, colours) and ice water content $\left(1 \times 10^{-8}, 5 \times 10^{-8}, 1 \times 10^{-8}\right.$ and $5 \times 10^{-8} \mathrm{~kg} \mathrm{~kg}^{-1}$, black contours) and (right) potential vorticity (PVU, colours) and ice water content. Wind vectors are also displayed.
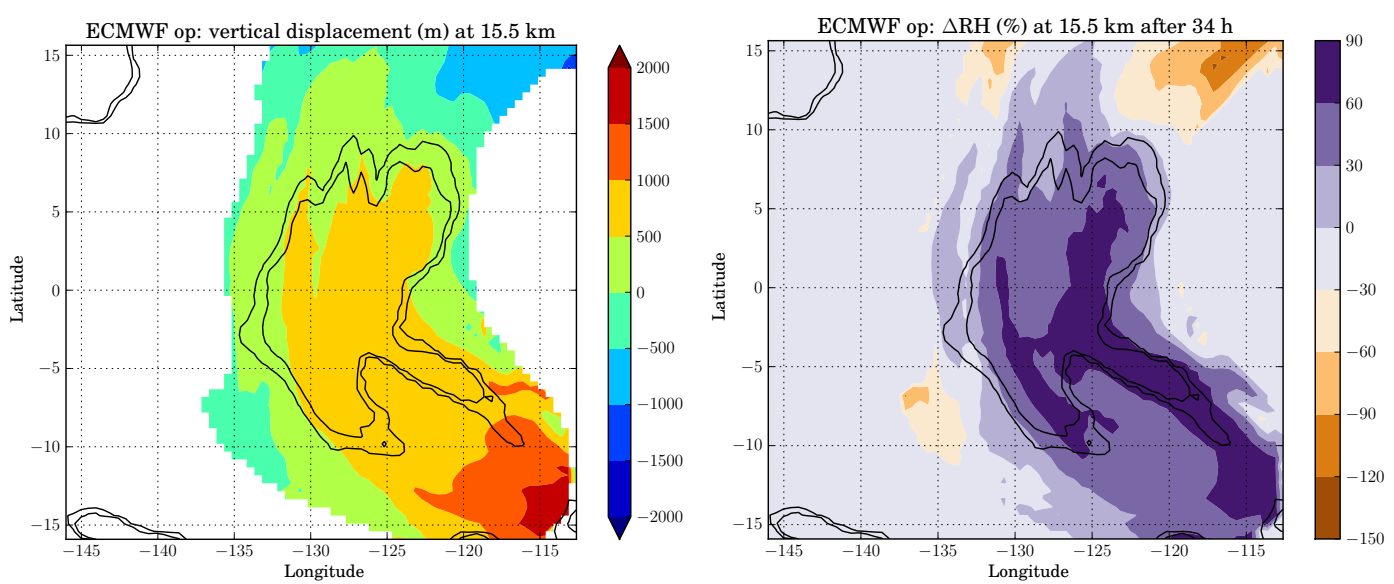

Figure 4. (Left) Lagrangian vertical displacement between the start of the simulation (27 January 2009, 00:00 UTC) and 28 January 2009, 10:00, after $34 \mathrm{~h}$ of simulation, displayed at the location of air parcels on 28 January, 10:00 UTC (altitude of 15.5 km). (Right) Contribution of vertical displacement to relative humidity change $\Delta \mathrm{RH}$ along a Lagrangian trajectory; see text for details.

and (right) antisymmetric components of the $125 \mathrm{hPa}$ temperature between $15^{\circ} \mathrm{S}$ and $15^{\circ} \mathrm{N}$, with zonal wind contours added on the left panel and meridional wind contours on the right. The symmetric signal shows quasi-stationarity features, which could be the signature of an equatorial Rossby wave. In contrast, the antisymmetric signal clearly shows westward phase propagation, and antisymmetric temperature are in phase with the meridional wind component. This moving pattern is consistent with the signature of a Yanai (or mixed Rossby gravity) wave and explains the antisymmetric structure in which the cirrus forms that was seen in Fig. 3, left panel. The Yanai wave interpretation is also consistent with the quadrature phase PV and antisymmetric temperature anomalies (Fig. 3, both panels).

The onset of this "Yanai wave" perturbation in the domain and its vertical structure are depicted more clearly in Fig. 6, which shows a vertical Hovmöller diagram of antisymmet- ric temperature and symmetric meridional wind at $130^{\circ} \mathrm{W}$. Meridional wind and antisymmetric temperature exhibit a downward phase propagation in the cirrus altitudes (in agreement with expectations for upward-propagating Yanai wave packets). It is worth noting that the "Yanai wave" perturbation seen here differs from the free-travelling Yanai waves observed in the equatorial lower stratosphere. Its period is longer ( $\sim 10$ days versus $4-5$ typically in the lower stratosphere) and its phase speed lower. This is probably due to several factors such as the low frequency of the PV perturbation that excites the wave-like response, Doppler shift, the interaction with the equatorial Rossby wave pattern and the complicated sheared wind structure (see Wang and Xie, 1996) over the Eastern Pacific at that time. Such long-period (6-10 days in our case) westward-propagating Yanai waves seem common in the westerly duct and have been observed in operational analyses by Randel (1992). 

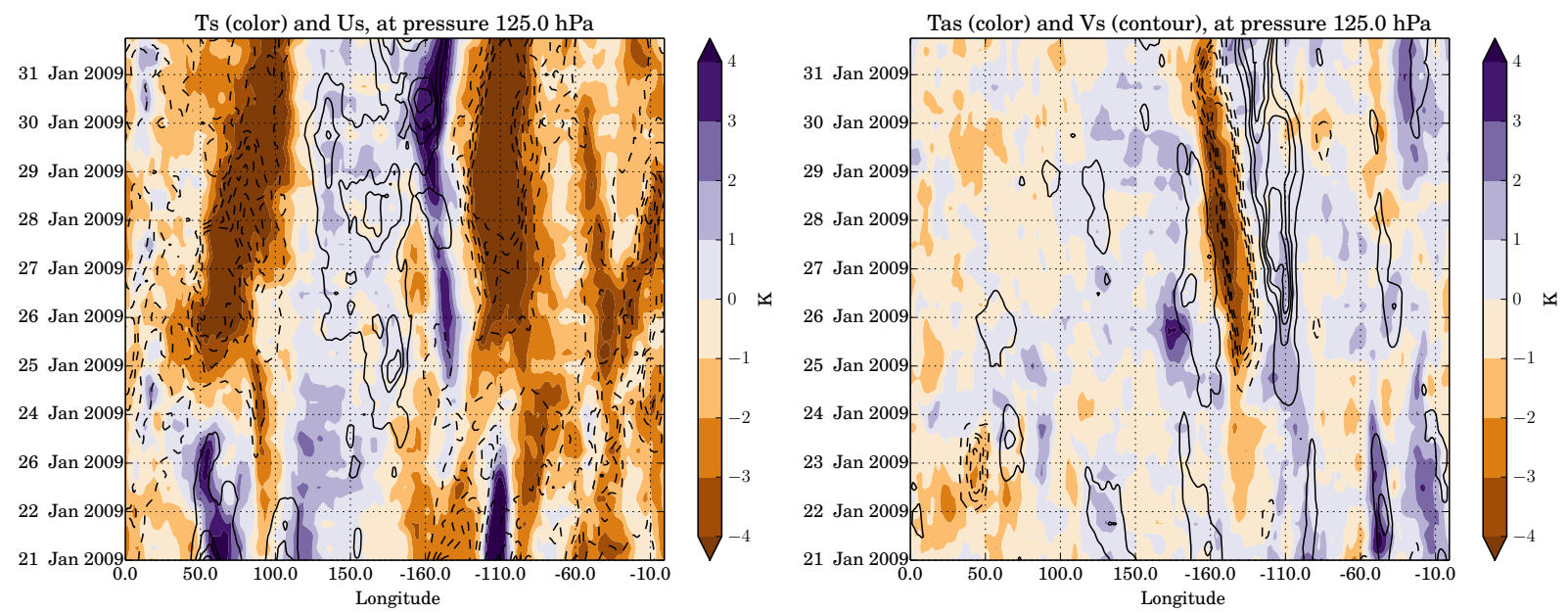

Figure 5. Hovmöller diagrams of (left) symmetric and (right) antisymmetric temperature anomalies in the ERA-Interim reanalysis. The averages are computed between $15^{\circ} \mathrm{N} / \mathrm{S}$ and antisymmetric stands for antisymmetric relative to the equator. On the right panel, the black contours correspond to positive (continuous) and negative (dashed) symmetric meridional wind anomalies. On the left panel, they correspond to symmetric zonal wind anomalies.

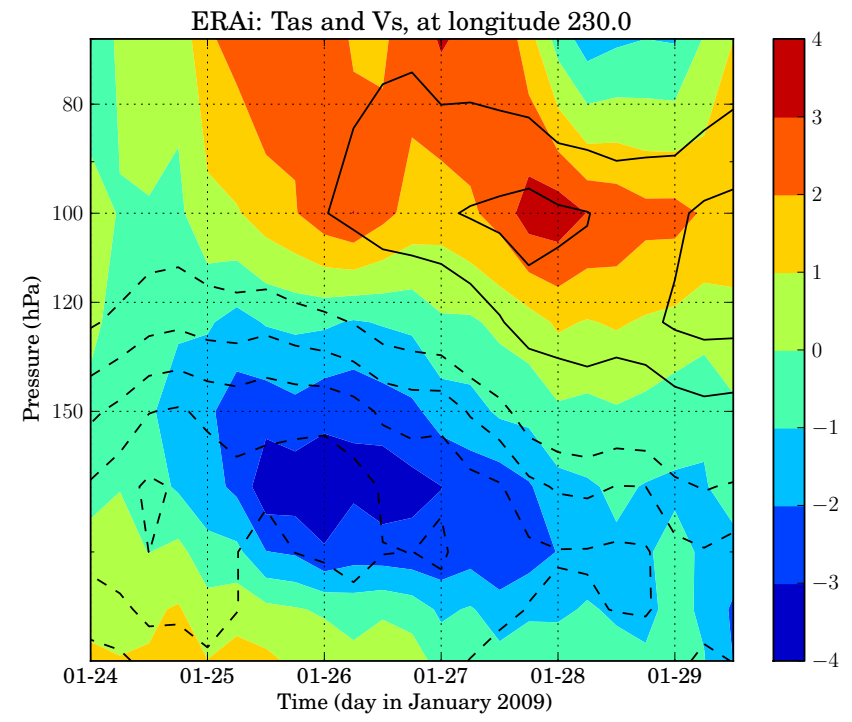

Figure 6. Hovmöller diagram of symmetric meridional wind (contours, dashed for negative values) and antisymmetric temperature anomalies (colour, K) in the ERA-Interim reanalysis, before and during the period of the simulation, at longitude $130^{\circ} \mathrm{W}$. The averages are computed between $15^{\circ} \mathrm{N} / \mathrm{S}$ and the antisymmetric stands for antisymmetric relative to the equator.

The combination of the symmetric and antisymmetric temperature signals creates negative temperature anomalies in the south-east part of the domain, which is also the region of strongest vertical displacements. Hence, the large-scale dynamics during the simulation is dominated by a PV intrusion originating from the midlatitudes that excites Yanai (and probably Rossby) equatorial wave modes, which are themselves responsible for the vertical displacements in the upper troposphere. These wave-induced vertical displacements are the necessary component to increase the supersaturation and cause the cirrus formation.

Although the main structure of the cirrus is dominated by the large-scale waves, other waves contributing to the vertical displacement might also have an impact on the temperature anomaly and may influence cirrus formation. However, for a given trajectory the spectrum of vertical displacements emphasizes more the contribution of motions with slower intrinsic frequencies. In the present case, where large-scale motions with significant vertical displacements are present, the contribution from smaller-scale motions (inertia gravity waves) to the vertical displacement needed to produce the cirrus clouds seems secondary to understand the cloud pattern.

\section{Sensitivity of the simulated cirrus cloud}

The large-scale uplift is thus a first-order element needed to produce the cirrus field. Accurate cirrus cloud simulations involve this and other components, ranging from a good description of the water vapour field to mesoscale gravity waves, as well as appropriate microphysics and radiative parameterizations. The sensitivity of the simulated cirrus to some of those components will be presented in the following subsections once the methodology for comparing the simulations is introduced. A summary of all simulations presented in this section can be found in Table 1.

\subsection{Comparison methodology}

Different characteristics of the cloud field should be compared between simulations and observations. Along a 
CALIOP track, cloud location and extension ("cloud fraction") are important properties to be evaluated on top of the averaged returned backscatter. Their evaluation depends on subjectively chosen thresholds for the cloud limits but can nevertheless provide more objective insights into the differences than a visual comparison. Cloud location and amplitude will be used to determine how the different simulations compare with the observations.

On top of the comparison with the observations, it is also necessary to conduct comparisons of the simulations with one another in order to capture the spatial structure better than only with the along-track view provided by CALIOP. We have used maps of the simulated ice water path (IWP; vertically integrated IWC) above $14 \mathrm{~km}$ for this purpose. The (dis)similarity of the obtained maps is evaluated using standard correlations and the SAL metrics, which have been introduced by Wernli et al. (2008) and previously used to evaluate cirrus simulations by Kienast-Sjögren et al. (2015). The SAL consists in three components: structure (S), amplitude (A) and location (L). A perfect match between the fields (exactly similar) corresponds to the score 0 for structure, amplitude and location. More precisely, the structure and amplitude components take values between -2 and 2 , while the location component is bounded by 0 and 2 . The structure compares the shape of the two cloud fields (many small clouds versus one huge cloud). Positive values indicate a more dispersed cloud field than the reference. The amplitude compares the average IWP, positive values corresponding to an overestimation relatively to the reference. This A component takes no consideration on the spatial structure. The last component, L, summarizes the error in the spatial location of the field (the location of its centre of mass).

The comparisons of the different fields with observations are presented in Table 4, which reports the differences in the vertical and horizontal location of the centroid of the returned backscatter between observation and simulations, as well as the differences in the amplitude of the returned backscatter (calculated as the A component of the SAL). The maps of the IWP above $14 \mathrm{~km}$ are shown in Fig. 7 and the corresponding correlations with the reference set-up and SAL metrics are reported in Table 5.

\subsection{Sensitivity to initial conditions}

Previous studies have shown TTL cirrus modelling to be strongly sensitive to initial conditions, for instance the initial water vapour content (Dinh et al., 2016). To assess this sensitivity, we have carried out different sets of simulations varying the initial and the boundary conditions (see Table 1). With two different microphysics schemes (Morrison and Thompson), we have performed simulations with ERAInterim and the ECMWF operational analysis initial and boundary conditions. The reference simulation uses the operational analysis for initialization and boundaries. We have also performed a nested model run with a coarser horizontal
Table 3. Average bulk microphysical properties (ice water content, ice crystal number and effective radius, $R_{\mathrm{eff}}$ ) of the simulated cirrus clouds at $15.5 \mathrm{~km}$ on 28 January, at 10:00, for different choice of the microphysics parameters $N_{\mathrm{IN}}$ and $S_{\text {nuc. }}$.

\begin{tabular}{lccr|rrr}
\hline$N_{\text {IN }}\left(\mathrm{L}^{-1}\right)$ & \multicolumn{3}{c|}{150} & & \multicolumn{3}{c}{1500} \\
\cline { 2 - 7 }$S_{\text {nuc }}$ & 0.08 & 0.20 & 0.45 & 0.08 & 0.20 & 0.45 \\
\hline Ice crystal & 72. & 32. & 9. & 85. & 41. & 9. \\
number $\left(\mathrm{L}^{-1}\right)$ & & & & & & \\
$R_{\text {eff }}($ microns) & 10.5 & 12.9 & 13.8 & 10.4 & 12.6 & 13.6 \\
Ice water & 0.09 & 0.07 & 0.03 & 0.10 & 0.07 & 0.03 \\
content $\left(\mathrm{mg} \mathrm{m}^{-3}\right)$ & & & & & & \\
\hline
\end{tabular}

Table 4. Differences in amplitude and in vertical and horizontal centroid location between the simulated and observed ATB (a proxy for cloud position), along CALIOP track on 28 January 2009, 10:00 h UTC.

\begin{tabular}{lrrr}
\hline Simulation name & Amplitude & $\begin{array}{r}\text { Latitude along } \\
\text { CALIOP track (degrees) }\end{array}$ & $\begin{array}{r}\text { Altitude } \\
(\mathrm{m})\end{array}$ \\
\hline Thompson & -0.32 & -2.71 & -293. \\
Thompson-ERAi & -1.08 & -7.4 & 80. \\
Thompson-nested & -1.13 & -3.4 & -39. \\
H2O+20\% & 0.83 & -2.9 & -820. \\
Morrison & -0.94 & -4.8 & 401. \\
Morrison-ERAi & -0.56 & -7.1 & 257. \\
\hline
\end{tabular}

resolution $(30 \mathrm{~km})$, which was launched on January 25 over a larger domain (extending from 27.5 to $27.5^{\circ} \mathrm{N}$ and from 158 to $102^{\circ} \mathrm{W}$ ) and initialized with the operational analysis. This simulation then served as initialization for another model run over our reference domain at $10 \mathrm{~km}$ resolution. This experiment can also be viewed as a sensitivity test to domain size. At last, we have conducted an additional simulation initialized with the operational analysis fields, but with a homogeneous $20 \%$ increase in the initial water vapour content. This bias is in the range of observed disagreements between the ECMWF operational analysis and in situ observations (Kunz et al., 2014). We emphasize that all those experiments are mainly illustrative and may not span the uncertainty linked to initial and boundary conditions.

Table 4 shows that the reference simulation offers the best agreement with the observations in amplitude and a close centroid location. The centre of mass of the attenuated backscatter is about $300 \mathrm{~m}$ (less than one model level) lower in this simulation than in observations. All simulations put the cloud centroid too much to the south, which is linked to an along-track underestimation of the northward extension of the cloud compared to observations. All simulations also underestimate the intensity of the ATB, except the one with increased initial water vapour. The change in the initial condition mainly results in a change in the location of the cloud. While in the nested simulation the mean cloud location is comparable to the reference, in the simulation initialized with 
Table 5. Correlation and SAL (see text for details) for the ice water path above $14 \mathrm{~km}$ in WRF simulations compared to the reference simulation at 12:00 on 28 January 2009. The "cloud threshold" for SAL was chosen to be a fourth of the maximum ice water path (see Wernli et al., 2008).

\begin{tabular}{lrrrr}
\hline Simulation name & Correlation & Amplitude & Structure & Location \\
\hline Thompson-ERAi & 0.54 & 0.26 & -0.58 & 0.14 \\
Thompson-nested & 0.47 & 0.36 & -1.46 & 0.20 \\
H2O+20\% & 0.93 & 0.34 & 0.34 & 0.02 \\
No heat & 0.97 & 0.04 & 0.29 & 0.02 \\
WSM5 & 0.89 & 0.54 & 0.14 & 0.12 \\
Morrison & 0.85 & 0.54 & 0.46 & 0.10 \\
Morrison-ERAi & 0.62 & 0.87 & 1.04 & 0.08 \\
Thompson- $S_{\text {nuc }}=0.08, N_{\text {IN }}=150$ & 0.99 & 0.036 & 0.046 & 0.004 \\
Thompson- $S_{\text {nuc }}=0.20, N_{\text {IN }}=150$ & 0.96 & -0.32 & -0.31 & 0.02 \\
Thompson- $S_{\text {nuc }}=0.20, N_{\text {IN }}=1500$ & 0.96 & -0.33 & -0.27 & 0.02 \\
Thompson- $S_{\text {nuc }}=0.45, N_{\text {IN }}=1500$ & 0.64 & -0.77 & -1.30 & 0.11 \\
\hline
\end{tabular}

the ERA-Interim the cloud is moved further southward (Table 4).

This effect of southward displacement of the cloud in the simulation with ERA-Interim is also shown in the IWP maps in Fig. 7. The cloud pattern is changed in the same way for the two microphysics schemes presented: the slightly different dynamics and water vapour in ERA-Interim simulations result in a cloud structure moved in the southern part of the domain. In terms of SAL metrics (Table 5), depending on the scheme, the amplitude in the ERA-Interim simulations are increased compared to those that use the operational analysis. This response is due to a moister initial condition in cirrus formation regions in the ERA-Interim simulations, and this prevails even though there are stronger uplifts in the northern part of the domain for simulations with the operational analysis. For the two schemes, the correlations with the reference are significantly decreased (below 0.65) when the ERA-Interim or the nested run are used for initialization. This mainly comes from a change in the location term. Finally, initial and boundary conditions are also the main factors affecting the S component of the SAL (Table 5).

We must emphasize that the sensitivity to the initial conditions refers in fact to both the initial dynamics of the simulation (e.g. initial distribution of the PV) and the initial relative humidity. To isolate one from the other, we have also performed a simulation with the ECMWF operational analysis initial and boundary winds and temperature, but with the ERA-Interim water vapour field (not shown). Our water vapour does not strongly affect the dynamics because of the limited occurrence of convection in the domain. The simulated cirrus is then very similar to the one obtained with the operational analysis fields in terms of location and structure; it shows higher IWC, consistently with the discussion above (moister ERA-Interim). This experiment highlights that, due to the importance of the uplifts and the strong vertical gradient of water vapour content, the cloud structure is controlled more by the dynamically induced vertical displacement than by the initial distribution of humidity. Consistently, a simulation with NCEP-CFSR winds and temperature conducted in early stages of this work led to a cirrus field with significant differences.

The specific effect of changing the initial relative humidity is also shown by the simulation with $20 \%$ increase of the water content. It has little effect on the horizontal characteristics of the cloud field (see the correlation, location or structure in Table 5). However, its effect is not limited to increasing the IWC; it also tends to lower the cloud altitudes (see Table 4) by bringing regions below the cloud in the reference simulation to supersaturation and hence prolonging vertically the fall streaks generated by the initial cloud.

\subsection{Some sensitivities to the microphysics}

As stated in the Introduction, there has been much debate regarding microphysical pathways of cirrus cloud formation (Spichtinger and Krämer, 2013). Recent measurements and modelling studies suggest that strong variability may be present at scales as small as a few metres (e.g. Jensen et al., 2013; Murphy, 2014; Dinh et al., 2016), unreachable in our model set-up. Hence we do not attempt to delve into the details of the microphysics. We evaluate the sensitivity to some microphysical assumptions by two simple approaches. First, we just take advantage of the schemes available in WRF to test how sensitive the simulated cirrus clouds are to changes within a range of standard parameterizations. Then, inside the Thompson scheme, we modify the ad hoc parameters for nucleation at low temperature: number of ice nuclei $N_{\mathrm{IN}}$ and supersaturation threshold for ice nucleation $S_{\text {nuc }}$.

\subsubsection{Sensitivity to the microphysical scheme in WRF}

We performed tests with one single-moment scheme (WSM5) and two double-moment schemes, the Thompson and Morrison schemes. All those schemes use the same very empirical approaches of the nucleation at low temperature 

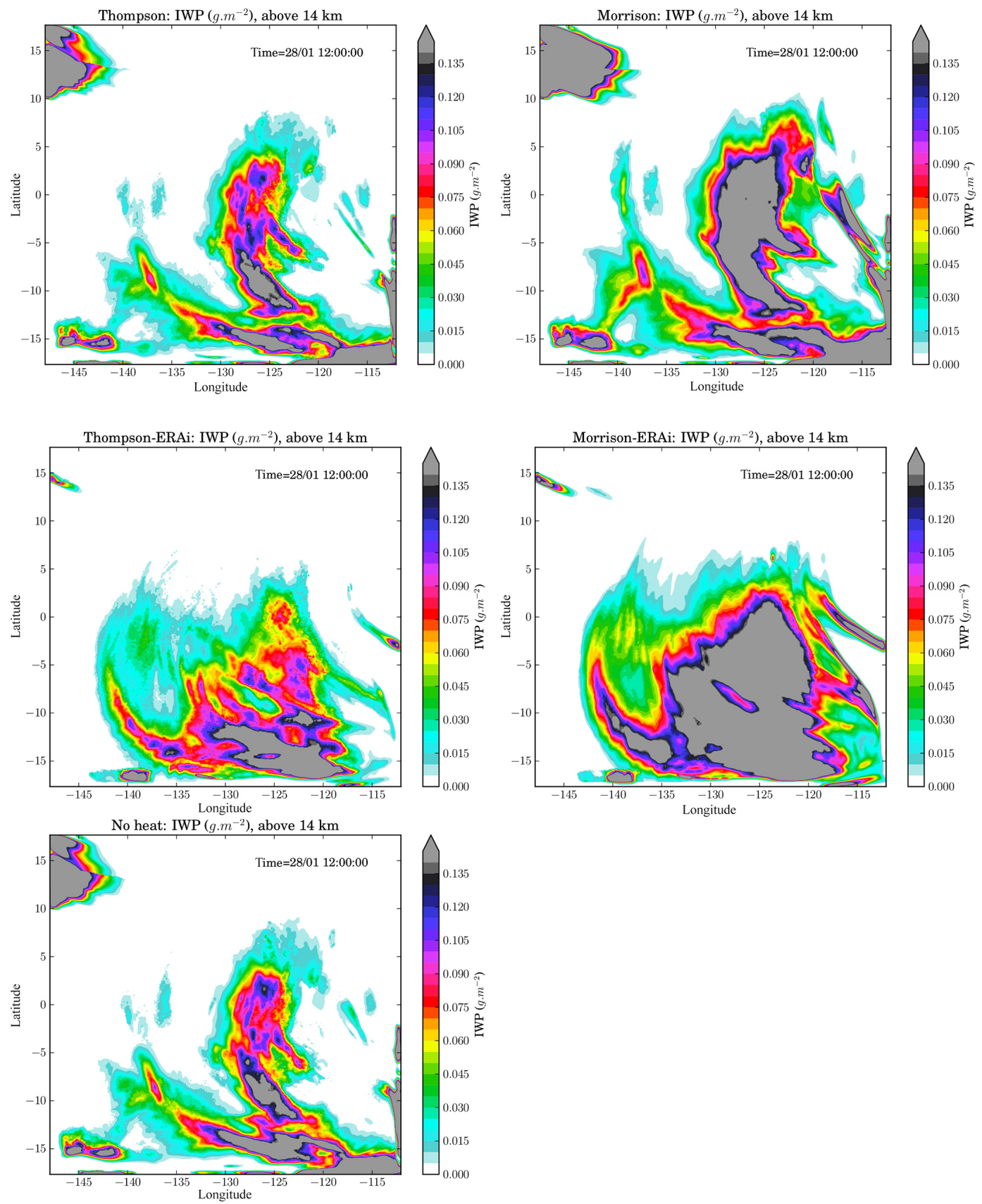

Figure 7. Maps of the ice water path above $14 \mathrm{~km}$ (vertically integrated ice water content) on 28 January 2009, at 12:00 UTC, in different simulations (see Table 1 for details): (top left) Thompson, (top right) Morrison, (middle left) Thompson-ERAi, (middle right) Morrison-ERAi and (bottom left) no heat.

as the Thompson scheme, but their different numerical treatments of sedimentation and growth lead to some sensitivity.

In Fig. 7, one can compare the IWP produced by the Thompson and Morrison schemes for the two initial and boundary conditions tested. The two schemes produce similar (correlated; see Table 5 for correlation with the reference) cloud fields, but their intensities differ. The Morrison simulation tends to have higher IWC than the Thompson simu- lation. The difference is mainly due to the integrated effect of sedimentation (it almost vanishes if sedimentation is suppressed), the Morrison scheme having a less efficient sedimentation (more details on the different treatments of sedimentation can be found in Appendix A). This lower downward flux of ice in the simulations with the Morrison scheme also explains that the cloud is higher in those compared to CALIPSO observations (see Table 4). Vertical profiles con- 
firm this effect of higher IWC in the Morrison scheme (not shown).

In terms of SAL metrics, Table 5 shows that the main component affected by the different choice in microphysics is the amplitude, i.e. the mean value of the IWP. However, the correlations are higher, and the structure and location components are more similar between the different schemes than between different initial and boundary conditions. Also, it appears clearly in this table that the different choices made in the two-moment schemes make them as dissimilar from one another as from the WSM5 one-moment scheme.

\subsubsection{Sensitivity to some bulk microphysics parameters: number of "ice nuclei" and supersaturation threshold for nucleation}

In order to explore further the sensitivity to microphysical parameters, we have also run sensitivity simulations with different supersaturation thresholds $S_{\text {nuc }}$ and "ice nuclei number" $N_{\text {IN }}$. Because our resolution is coarse relative to what is needed to resolve microphysical processes, we emphasize that the chosen supersaturation threshold is not meant to fit experimental data of homogeneous or heterogenous nucleation. Rather, it has to account for the fact that, within one model grid box, temperature and/or water vapour fluctuations will cause the relative humidity to rise above the actual (experimentally measured) threshold for the particles that are present, while the grid box average remains below this value (Kärcher and Burkhardt, 2008). However, the chosen value is ad hoc and the sensitivity to this parameter should be assessed. Besides the default value of $8 \%$, we have tested values for threshold supersaturation of 20,30 and $45 \%$. As $N_{\text {IN }}=1500 \mathrm{~L}^{-1}$ may appear strong as a default value for the grid-box-mean effect of nucleation, we have tested reducing $N_{\text {IN }}$ to $150 \mathrm{~L}^{-1}$.

Figure 8 shows maps of the IWP above $15 \mathrm{~km}$ for two simulations, with the Thompson scheme keeping the same $N_{\text {IN }}=1500 \mathrm{~L}^{-1}$ and varying the supersaturation threshold $\left(S_{\text {nuc }}=0.2\right.$ and 0.45$)$; these figures can also be compared to the reference simulation in the top left panel of Fig. 7. They show that, over some range of $S_{\text {nuc }}$, the large-scale cloud field is only weakly dependent on $S_{\text {nuc }}$ : between $S_{\text {nuc }}=0.08$ and $S_{\text {nuc }}=0.2$, there is only a change in the absolute IWP value, which is diminished due to more grid point not experiencing nucleation and remaining ice free. This ice mass decrease can also be seen in Table 5 in the A component of the SAL. Despite the amplitude difference, the general cloud pattern is itself very similar between the simulations with $S_{\text {nuc }}=0.08$ and $S_{\text {nuc }}=0.2$, as confirmed by the strong correlation with the reference (Table 5). When a critical value for the threshold is exceeded, however, nucleation does not happen in some parts of the cloud and the pattern is much affected; this is the case for the experiment with $S_{\text {nuc }}=0.45$. Changing $N_{\text {IN }}$ between $N_{\text {IN }}=150$ and $N_{\text {IN }}=1500 \mathrm{~L}^{-1}$ had only a minor impact on the large-scale properties of the simu- lated cloud field (Table 5), which may result from an increase in the portion of the cloud experiencing nucleation.

The overall bulk microphysical properties of the clouds are relatively weakly affected by the change, as reported in Table 3. We emphasize that this is very different from parcel model results, because the area covered by the clouds changes from a simulation to the other and because we select only cloudy air (i.e. with IWC bigger than $5 \times 10^{-1} \mathrm{~kg} \mathrm{~kg}^{-1}$ ) to compute the statistics. $N_{\text {IN }}$ has a limited impact. $S_{\text {nuc }}$ variation creates much more substantial variability. However, this stays within the variability observed in TTL cirrus clouds, which scans several orders of magnitude (Jensen et al., 2013).

Overall, the results of those experiments show that there is robustness of the simulated cirrus large-scale and microphysical properties for a range of parameter values, which lie within reasonable values. This is reassuring given the uncertainty of those parameters in our simulation framework.

\subsection{Sensitivity to radiation}

Previous real-case studies have shown that interaction with radiation could have a strong influence on the high cloud field evolution for midlatitude cases (Gu et al., 2011). Idealized simulations suggest that this may also be the case for TTL cirrus, at least under specific environmental conditions (Dinh et al., 2010; Jensen et al., 2011). In Fig. 7, the IWP from simulations with (top) and without (bottom) cloud radiative effect included is displayed. There is little difference between the two simulations, and this is confirmed by the very high correlation (0.97) and the small amplitude component of the SAL metrics (Table 5). On this timescale $(36 \mathrm{~h}$ after the beginning of the simulation), it seems that there is little impact on the cirrus field. We will discuss possible reasons for this negligible impact of the radiation in our case in Sect. 5 .

\subsection{Resolution}

It should be noted that the results we present are for a specific resolution, which is probably too low to adequately simulate some of the processes at stake. Nevertheless, increasing the vertical resolution by a factor of 2 or the horizontal one by a factor of 2.5 created few quantitative changes to the simulated cirrus cloud field. This illustrates that in our set-up and with our typical resolution (a few kilometres in the horizontal and a few hundred metres in the vertical), sensitivity to resolution has not yet appeared. This is also linked to the relative lack of convection in the domain and to the first-order influence of the forcing provided by the large-scale dynamics.

\subsection{Summary of sensitivities}

For our cirrus case, the combination of the correlations and of the amplitude component of the SAL metrics in Table 5 allows some ranking of sensitivities. The dynamics are of 

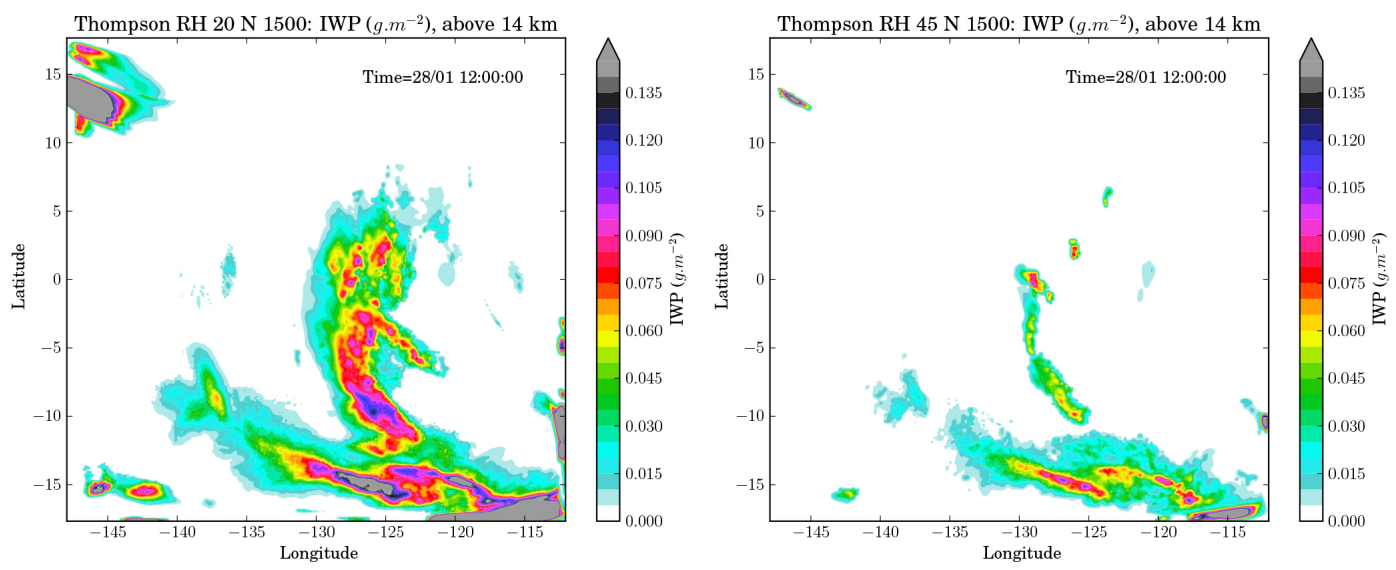

Figure 8. Maps of the ice water path above $14 \mathrm{~km}$ (vertically integrated ice water content) on 28 January 2009, at 12:00 UTC, in simulations using the Thompson scheme with different supersaturation threshold for ice formation (see Sect. 4.3 .2 for details): (left) $S_{\text {nuc }}=0.2$ and (right) $S_{\text {nuc }}=0.45$.

first order, although after $36 \mathrm{~h}$ of simulation the impact of microphysics and initial water vapour are also important. The choices of the parameterization of microphysical processes and of the initial water content do not affect the cloud field in the same manner as dynamics; they mainly influence the cloud "amplitude" and vertical position. The "dry" dynamical initial and boundary conditions (winds and temperature), as well as the different dynamics and water vapour field they create through different advection, are more important to determine the cloud structure and location and have the strongest impact on correlations. The relatively moderate role of details in the water vapour field is reassuring because this quantity is poorly known at fine scale in the TTL. It explains why we obtain a good agreement with the observations without any tuning of the initial water vapour. Finally, Table 5 shows that, in our case, the cloud radiative effect results in much less sensitivity than the other factors because of the relatively low heating rates.

\section{Discussion}

\subsection{Evaluation of the cirrus radiative impact in the TTL}

Cirrus clouds are believed to strongly influence the radiative budget of the TTL by increasing the radiative heating rates. In this region of low positive heating rates, even a small contribution from cirrus could significantly enhance the transport efficiency and strongly lower the transit time of ascending air parcels from the TTL to the stratosphere (Corti et al., 2006). Based on the satisfactory agreement with observations (see Sect. 2.3), our simulations allow us to provide a reliable estimate of the radiative impact of this specific cloud in the tropical tropopause layer. To evaluate this, we have performed simulations with the cloud radiative heating ar-

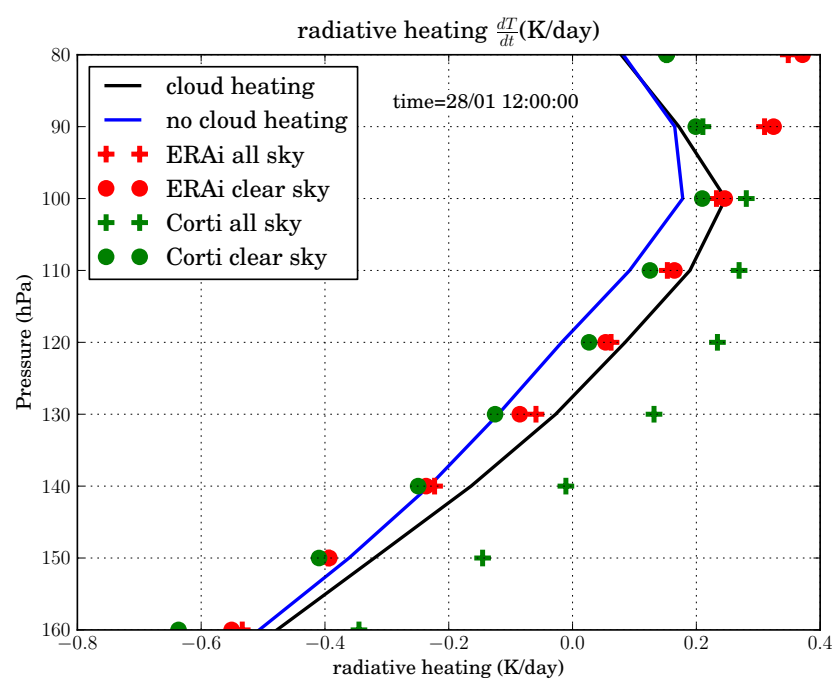

Figure 9. Profiles of radiative heating rates on 28 January 2009, 12:00 UTC, in the WRF domain, for the simulations with (black) and without (blue) cloud heating included. For comparison, the $3 \mathrm{~h}$ averaged clear-sky and all-sky radiative heating rates in the ERAInterim reanalysis are shown in red, together with the estimates from Corti et al. (2006) for clear-sky and all regions in green.

tificially turned off in the RRTMG scheme. The resulting profiles of radiative heating rates averaged over the domain are shown in Fig. 9. For comparison, the same profiles in the ECMWF ERA -Interim reanalysis and the zonal annual mean profiles calculated by Corti et al. (2006) are also displayed for clear and all-sky radiative heating rates. Note that the heating rates profiles displayed here are in actual temperature tendency and not in potential temperature tendency.

In the upper TTL (above $90 \mathrm{hPa}$ ), the WRF simulation seems to underestimate the heating rates compared to the ERA-Interim. They are in better agreement with Corti et al. 


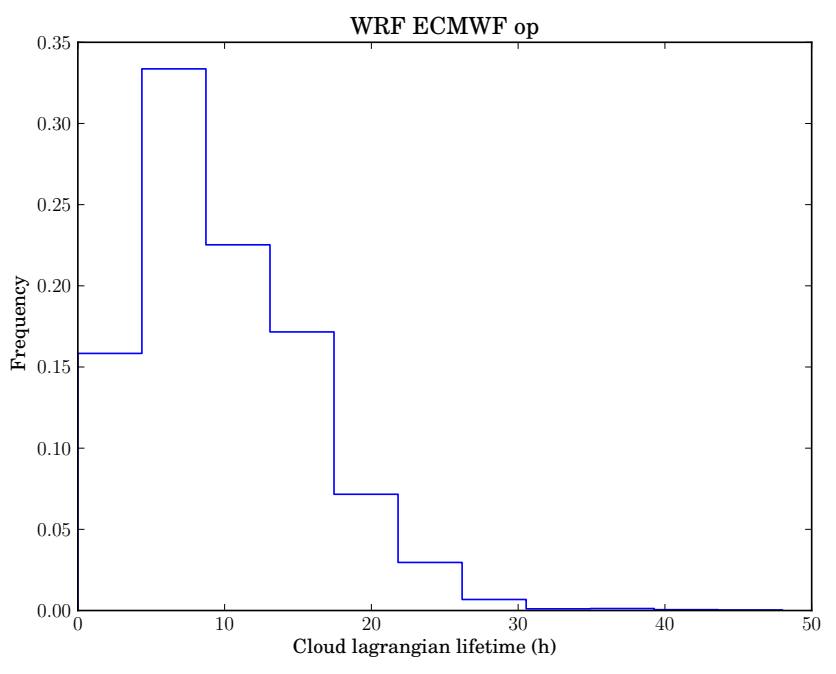

Figure 10. Distribution of in-cloud residence time for air parcels, estimated from Lagrangian trajectories launched on 28 January 2009, 12:00, in the reference simulation and calculated forward and backward. Parcels were considered in cloud when the ice water content was bigger than $1 \times 10^{-8} \mathrm{~kg} \mathrm{~kg}^{-1}$.

(2006). This disagreement mainly comes from long-wave differences and might be due to different ozone mixing ratios, but it was not investigated further as it is above the main levels of interest.

In the lower part of the TTL (below $90 \mathrm{hPa}$ ), there is a fair agreement between the heating rates in the ERA-Interim and in the WRF simulation, which use different versions of the same RRTMG scheme, as well as with those estimated by Corti et al. (2006). However, the difference between clearand all-sky heating rates in the reanalysis is very limited, while there is a significant enhancement of the heating in the simulations even after averaging over the whole domain. From the difference between the WRF simulations with and without cloud radiative heating included, we estimate the domain-averaged cloud radiative effect to be of the order of $0.1 \mathrm{Kday}^{-1}$. This contribution moves the level of zero radiative heating by about $10 \mathrm{hPa}$ (i.e. about $500 \mathrm{~m}$ ) below its clear-sky value. This is a factor of about 2-3 smaller than the estimates by Corti et al. (2006) for the whole tropics shown on the figure, which is probably due to geographic heterogeneities of the cloud field in the tropics with much colder and denser clouds in the Western Pacific boreal winter. We also emphasize that this is a domain average, but instantaneous values in the cloud can be much more substantial, reaching up to $1.5-2 \mathrm{Kday}^{-1}$. This is comparable to estimates of the order of $1-3 \mathrm{Kday}^{-1}$ observed by Bucholtz et al. (2010) but higher than values in subvisible cirrus reported by Davis et al. (2010). This figure also stresses that a poor representation of the cirrus in the reanalysis probably leads to an underestimation of the additional heating rate induced by the cloud.

\subsection{Absence of a cloud-scale (re)circulation and observed cloud duration}

Recent studies (e.g. Dinh et al., 2012; Jensen et al., 2011) have examined how cloud-induced radiative heating could drive cloud-scale circulation in TTL cirrus. Among other results, the magnitude of wind shear was found to be an important factor affecting the buildup of cloud-scale circulations (Jensen et al., 2011).

We examined the dynamical impact of cloud radiative heating for our simulated cirrus by comparing the simulations with and without cloud radiative heating. Only minor differences were found for the cirrus evolution (see Table 5). Although the situation was a priori ideal for a cloud-scale circulation to build (cloud above the ocean, with little convection below), several factors can explain its absence in our simulations. First, our radiative heating rates are too low to generate such a circulation, although they are comparable to the lower values reported in the literature for modelling studies (e.g. Dinh et al., 2012). Then, our vertical resolution of $300 \mathrm{~m}$ may be too coarse to resolve this recirculation in the cloud and its surrounding. However, increasing the vertical resolution by a factor of 2 did not produce any significant change. Going back to physical reasons, Jensen et al. (2011) suggested that, in most cirrus, the Lagrangian temperature variability along an air parcel trajectory was such that it would limit the cloud lifetime, which would then be too short for a radiatively induced circulation to build. We estimated the in-cloud residence time using Lagrangian trajectories: forward and backward trajectories were calculated from initial positions within the cloud (IWC higher than $1 \times 10^{-8} \mathrm{~kg} \mathrm{~kg}^{-1}$ ), spaced every $1^{\circ}$ in latitude and longitude and every $500 \mathrm{~m}$ in the vertical.

The resulting probability density functions for the in-cloud residence time of air parcels is displayed in Fig. 10. The typical lifetime is less than $10 \mathrm{~h}$, which is probably too short for a radiative circulation to build and have significant impact on the cloud evolution. This result for our cirrus is in agreement with what was found for different TTL cirrus by Jensen et al. (2011).

On top of this cloud-lifetime limitation, there is another reason explaining the absence or at least the very limited impact of a cloud-scale (re-)circulation in our test case: the amplitude of this circulation. It will obviously depend on the background stability and heating efficiency, but idealized studies (Dinh et al., 2010, 2012) suggest that, in the most favourable cases and in a 2-D setting, those circulations will not exceed a few $\mathrm{ms}^{-1}$ in the horizontal and a few $\mathrm{cms}^{-1}$ on the vertical. These velocities and the associated shears are at most comparable to and often smaller than the ambient velocities and shears (e.g. the amplitude of cirrus-induced wind shear in idealized simulations reaches at most $5 \mathrm{~m} \mathrm{~s}^{-1} \mathrm{~km}^{-1}$; Dinh et al., 2012). In the vertical, typical large-scale to mesoscale motions which generate cirrus formation and cause cirrus dissipation can be of the order of 
a few $\mathrm{cm} \mathrm{s}^{-1}$. Hence, in cases such as ours, the radiatively induced vertical motions are not strong enough to come out relative to other motions present.

Finally, the set of simulations we have performed suggests that even if TTL cirrus appear to last several days, as suggested by Taylor et al. (2011), this can rather correspond to a succession of distinct clouds forming in a region of persistent favourable conditions. As for orographic lenticular clouds that can persist above mountains, the cloudy air parcels in the TTL cirrus clouds in our region are different through the cloud presence time. Cloud radiative heating seems not to have an important impact on the dynamics in our specific case and it is probably not required to explain the long duration of the cloud.

\subsection{Cloud-induced vertical redistribution of water vapour}

One major issue associated with TTL cirrus is the water vapour redistribution, which produces the irreversible dehydration (freeze-drying) experienced by air parcels that transit through the TTL before entering the stratosphere. Dinh et al. (2014) have used idealized simulations to illustrate that different scenarios for water vapour redistribution could arise depending on the cloud environment, with layers being dehydrated and others rehydrated. Similar estimates are not possible in our modelling configuration, because we do not use periodic boundary conditions. In our limited area simulations, there are air and water mass fluxes leaving and entering the domain through its boundaries. To nevertheless provide an estimate of the water redistribution due to the cloud field, we have introduced a passive water tracer in the simulations. The water tracer is advected and diffused using the same numerics as the moisture field (positive definite advection) but it is not subject to any physical, or more precisely microphysical, source nor sink. We evaluate the integrated impact of those microphysical sources and sinks, i.e. the vertical redistribution of water by the cloud, through the difference between the unaffected (advected only) water vapour field and the fully microphysically interactive water vapour.

Figure 11 shows the profile of the difference between microphysically passive and active water. To avoid being affected by the boundary conditions, we have introduced a second passive tracer for the "inner domain", i.e. the part of the domain whose air was inside the domain at the initial time. We have computed the difference only over this area, which depends on the altitude range considered due to wind vertical shear. Hence, the passive water is affected by exchange with air coming from the boundaries only in a limited "diffusion" range. This is less true for the active water due to the sheared vertical structure of our "inner domain" which, combined with ice sedimentation, may cause a water transfer due to ice falling from the "outer" into the "inner domain". That is why we can only provide a rough estimate of the vertical redistribution of water in the simulation. Here, three coloured curves are shown for three different simulations. The green curve corresponds to a "no sedimentation" test in which we artificially suppressed sedimentation for temperatures below $220 \mathrm{~K}$ (the cirrus regime); the consistency of our calculation is validated by the closeness of this curve to a $0 \mathrm{ppmv}$ change in total water above $14 \mathrm{~km}$. The blue curve shows the evaluation of redistribution for the Thompson scheme; with this scheme the cirrus dehydrates by about $0.5 \mathrm{ppmv}$ above $15.5 \mathrm{~km}$ and rehydrates below this altitude (by about $0.5 \mathrm{ppmv}$ ). Finally, the red curve corresponds to a "maximum dehydration" simulation in which the microphysics in the cirrus regime has been replaced by a simple hypothesis of removal of all water above $100 \%$ relative humidity with respect to ice (there is no ice for this simulation). Comparison of the red and blue curves illustrates the overestimation of dehydration and the missed rehydration made with this hypothesis, which is close to what has been used for Lagrangian trajectory modelling of stratospheric water vapour (e.g. Fueglistaler and Haynes, 2005).

We emphasize that the calculated redistributions are very dependent on the microphysical scheme and microphysical assumptions. Nevertheless, our simulations show the importance of the vertical redistribution of water associated with dehydration, which is known but may have been previously overlooked. Indeed, the dominant paradigm in calculations on dehydration along Lagrangian trajectories (e.g. Liu et al., 2010 ) is that the water vapour source is exclusively from below and that the last dehydration (i.e. coldest point along the trajectory) determines the water vapour concentration of air entering the stratosphere. This neglects the possibility of rehydration by sedimenting crystals, which constitutes another source of water vapour. Moreover, because of horizontal and vertical heterogeneities in the dehydration patterns, hydration by sedimenting ice crystals can modulate these patterns and the intensity of dehydration. In particular, Fueglistaler et al. (2014) recently illustrated that the stratospheric water response to a temperature drop associated with an increase in tropical upwelling would not follow the Clausius-Clapeyron scaling. By reducing the residence time of air in the TTL and thus the probability of air parcels to experience the coldest TTL temperatures (bounded in some geographic regions), the vertical velocity increase mitigates the temperature drop effect. If the TTL residence time indeed contributes to control dehydration, it is probable that rehydration (from in situ cirrus or anvil ice) does not fully cancel out before entering the stratosphere. In any case, limited (by microphysical processes) dehydration or rehydration (by sedimenting ice crystals) certainly contributes to influence the amount of water vapour and ice in the TTL.

\section{Conclusions}

We have performed a case study of large-scale cirrus clouds in the Eastern Pacific using a mesoscale model, the Weather 

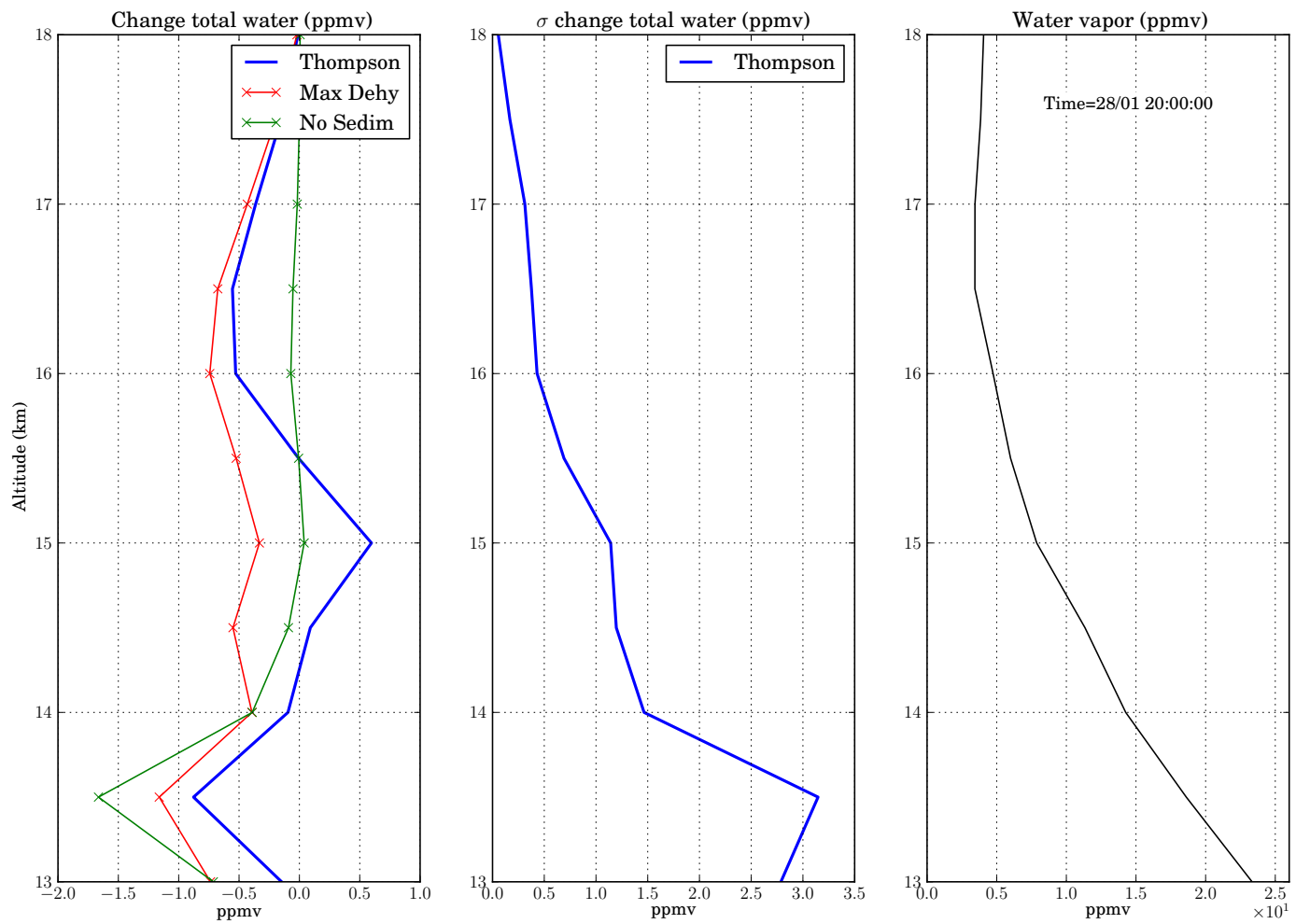

Figure 11. (Left) Change in water vapour between the start of the simulation (27 January 2009, 00:00) and 28 January 2009, 20:00, i.e. after $44 \mathrm{~h}$ of simulation, for three simulations: "Thompson" in blue (Thompson microphysics scheme), "Max Dehy" or "Maximum Dehydration" in red (removal of water vapour above $100 \%$ relative humidity) and "No Sedim" or "no sedimentation" in green (sedimentation turned off for temperatures below $220 \mathrm{~K}$ ). See text for details of the methodology of evaluation of the redistribution. (Middle) Standard deviation of the water redistribution for the "Thompson" full microphysics case; this emphasizes the variability and uncertainty in the estimate. (Right) Mean water vapour profile in the simulations.

Research and Forecast model (Skamarock et al., 2008). These simulations complement the previous study of the same case by Taylor et al. (2011), which was based on observations, and test the ability of the WRF model to reproduce cirrus clouds in the tropical tropopause layer. The simulations compare well with CALIPSO observations, suggesting that the dynamical processes leading to the cirrus formation are well captured by the model. They confirm that the cirrus forms in situ due to large-scale uplift associated with the response to a midlatitude potential vorticity intrusion. At the equator, this PV intrusion excites an equatorial wave response, mainly Yanai (mixed Rossby gravity) and equatorial Rossby modes that are modulated by faster inertio-gravity waves. The vertical displacements associated with this atmospheric flow are of the order of $1000 \mathrm{~m}$ in $30 \mathrm{~h}$ (equivalent to a mean cooling rate of $-8 \mathrm{~K} \mathrm{day}^{-1}$ ) and generate an increase in the relative humidity which is responsible for the formation of the cirrus clouds. Although the cloud forms in regions of relatively weak winds and has a large horizontal extent (several hundreds to more than a thousand of kilometres), trajectory calculations show that air parcels transit through the cirrus on timescales of about half a day.
This study highlights the importance of dynamical forcing in TTL cirrus formation: large-scale uplift associated with low-frequency perturbations provides the necessary drop in temperature for the cloud to form. The presence of the cirrus is robust between the two analysis systems tested (the ECMWF ERA-Interim reanalysis and operational analysis), because they both resolve the PV intrusion, which is a largescale feature. The simulated clouds are sensitive not only to the dynamics but also to the microphysical scheme and the distribution of water vapour, in different ways: differences in the dynamics affect the location, amplitude and structure of a cloud field, while the microphysics and water vapour mainly influence the intensity of the cloud and its vertical position and extent. The strong dependence to the dynamics, i.e. to the initial and boundary conditions provided by analyses, implies a serious difficulty for real-case simulations, because analyses notoriously have deficiencies in the description of winds in the TTL (Podglajen et al., 2014). In contrast to the sensitivity to dynamics and microphysics, the simulated cloud showed little sensitivity to radiation. More precisely, the simulations showed no evidence of a circulation on the scale of the cloud driven by radiative effects, likely because the cloud 
residence times are short (half a day) and the radiatively induced heating rates are rather weak. As this result might be tied to the specific environment in which the cloud develops (e.g. its relatively warm temperature of about $190 \mathrm{~K}$ ), more real-case simulations are needed in the future to evaluate the impact of cloud radiative heating on the dynamics in different environments.

Finally, the simulations illustrate the importance of dehydration and its associated rehydration in the TTL. This is important to understand not only the entry of stratospheric water vapour but also the water budget of the TTL itself. We emphasize that the latter is also of importance and has non-negligible impacts for the top of the atmosphere radiative fluxes (Riese et al., 2012). 
Appendix A: Ice sedimentation in Thompson and Morrison schemes

In the version of the Thompson scheme used in this work, the sedimentation fall speed of a single ice crystal depends on its diameter $D$ under the form

$v(D)=\left(\frac{\rho_{0}}{\rho}\right)^{0.5} \alpha D^{\beta}$.

The coefficients are $\alpha=1847.5$ and $\beta=1$; they have been chosen to produce a smooth transition with the snow category (Thompson et al., 2008). In the Morrison scheme, ice sedimentation follows

$v(D)=\left(\frac{\rho_{0}}{\rho}\right)^{0.35} a D^{b}$,

where $a=700$ and $b=1$; at the considered altitudes, there is a factor of 2 to 3 between the fall speeds in the Morrison and Thompson's schemes, which explains the higher IWC observed in the Thompson scheme. 
Acknowledgements. The authors are grateful to Sophie Bastin, Marjolaine Chiriaco and Hélène Chepfer for help with the COSP. We thank Martina Krämer, Jens-Uwe Grooß, Joan Alexander, Eric Jensen and Bill Randel for helpful discussions, and Pasquale Sellitto and three anonymous reviewers for their insightful comments on the manuscript. Aurélien Podglajen and Riwal Plougonven received support from École Polytechnique's Chaire pour le Développement Durable (DDX). Riwal Plougonven, Albert Hertzog, Bernard Legras and Aurélien Podglajen acknowledge support from ANR project StraDyVariUS (Stratospheric Dynamics and Variability, ANR-13-BS06-0011-01) and from EU project StratoClim. The support of CNES through "Stratéole" project is also acknowledged.

Edited by: P. Haynes

\section{References}

Bucholtz, A., Hlavka, D. L., McGill, M. J., Schmidt, K. S., Pilewskie, P., Davis, S. M., Reid, E. A., and Walker, A. L.: Directly measured heating rates of a tropical subvisible cirrus cloud, J. Geophys. Res., 115, D00J09, doi:10.1029/2009JD013128, 2010.

Chepfer, H., Bony, S., Winker, D., Chiriaco, M., Dufresne, J.-L., and Sèze, G.: Use of CALIPSO lidar observations to evaluate the cloudiness simulated by a climate model, Geophys. Res. Lett., 35, 1944-8007, doi:10.1029/2008GL034207, 2008.

Cirisan, A., Luo, B. P., Engel, I., Wienhold, F. G., Sprenger, M., Krieger, U. K., Weers, U., Romanens, G., Levrat, G., Jeannet, P., Ruffieux, D., Philipona, R., Calpini, B., Spichtinger, P., and Peter, T.: Balloon-borne match measurements of midlatitude cirrus clouds, Atmos. Chem. Phys., 14, 7341-7365, doi:10.5194/acp14-7341-2014, 2014.

Corti, T., Luo, B. P., Peter, T., Vömel, H., and Fu, Q.: Mean radiative energy balance and vertical mass fluxes in the equatorial upper troposphere and lower stratosphere, Geophys. Res. Lett., 32, L06802, doi:10.1029/2004GL021889, 2005

Corti, T., Luo, B. P., Fu, Q., Vömel, H., and Peter, T.: The impact of cirrus clouds on tropical troposphere-to-stratosphere transport, Atmos. Chem. Phys., 6, 2539-2547, doi:10.5194/acp-6-25392006, 2006.

Cziczo, D. J., Froyd, K. D., Hoose, C., Jensen, E. J., Diao, M., Zondlo, M. A., Smith, J. B., Twohy, C. H., and Murphy, D. M.: Clarifying the dominant sources and mechanisms of cirrus cloud formation., Science, 340, 1320-1324, doi:10.1126/science.1234145, 2013.

Davis, S., Hlavka, D., Jensen, E., Rosenlof, K., Yang, Q., Schmidt, S., Borrmann, S., Frey, W., Lawson, P., Voemel, H., and Bui, T. P.: In situ and lidar observations of tropopause subvisible cirrus clouds during TC4, J. Geophys. Res., 115, D00J17, doi:10.1029/2009JD013093, 2010.

Dinh, T., Durran, D. R., and Ackerman, T.: Maintenance of tropical tropopause layer cirrus, J. Geophys. Res., 115, D02104, doi:10.1029/2009JD012735, 2010.

Dinh, T., Durran, D. R., and Ackerman, T.: Cirrus and water vapor transport in the tropical tropopause layer - Part 1: A specific case modeling study, Atmos. Chem. Phys., 12, 9799-9815, doi:10.5194/acp-12-9799-2012, 2012.
Dinh, T., Fueglistaler, S., Durran, D., and Ackerman, T.: Cirrus and water vapour transport in the tropical tropopause layer - Part 2: Roles of ice nucleation and sedimentation, cloud dynamics, and moisture conditions, Atmos. Chem. Phys., 14, 12225-12236, doi:10.5194/acp-14-12225-2014, 2014.

Dinh, T., Podglajen, A., Hertzog, A., Legras, B., and Plougonven, R.: Effect of gravity wave temperature fluctuations on homogeneous ice nucleation in the tropical tropopause layer, Atmos. Chem. Phys., 16, 35-46, doi:10.5194/acp-16-35-2016, 2016.

Evan, S., Rosenlof, K. H., Dudhia, J., Hassler, B., and Davis, S. M.: The reWater Vapor Measurement Biases in the Tropical Tropopause Layer: Aura Microwave Limb Sounder vs Frost Point Hygrometerspresentation of the TTL in a tropical channel version of the WRF model, J. Geophys. Res.-Atmos., 118, 28352848, doi:10.1002/jgrd.50288, 2013.

Fueglistaler, S. and Haynes, P. H.: Control of interannual and longer-term variability of stratospheric water vapor, J. Geophys. Res., 110, D24108, doi:10.1029/2005JD006019, 2005.

Fueglistaler, S., Dessler, A. E., Dunkerton, T. J., Folkins, I., Fu, Q., and Mote, P. W.: Tropical tropopause layer, Rev. Geophys., 47, RG1004, doi:10.1029/2008RG000267, 2009.

Fueglistaler, S., Liu, Y. S., Flannaghan, T. J., Ploeger, F., and Haynes, P. H.: Departure from Clausius-Clapeyron scaling of water entering the stratosphere in response to changes in tropical upwelling, J. Geophys. Res.-Atmos., 119, 1962-1972, doi:10.1002/2013JD020772, 2014.

Gu, Y., Liou, K. N., Ou, S. C., and Fovell, R.: Cirrus cloud simulations using WRF with improved radiation parameterization and increased vertical resolution, J. Geophys. Res.-Atmos., 116, 2156-2202, doi:10.1029/2010JD014574, 2011.

Hong, S.-Y., Dudhia, J., and Chen, S.-H.: A Revised Approach to Ice Microphysical Processes for the Bulk Parameterization of Clouds and Precipitation, Mon. Weather Rev., 132, 103-120, 2004.

Iacono, M. J., Delamere, J. S., Mlawer, E. J., Shephard, M. W., Clough, S. A., and Collins, W. D.: Radiative forcing by longlived greenhouse gases: Calculations with the AER radiative transfer models, J. Geophys. Res.-Atmos., 113, 2156-2202, doi:10.1029/2008JD009944, 2008.

Jensen, E. and Pfister, L.: Transport and freeze-drying in the tropical tropopause layer, J. Geophys. Res., 109, D02207, doi:10.1029/2003JD004022, 2004.

Jensen, E. J., Toon, O. B., Pfister, L., and Selkirk, H. B.: Dehydration of the upper troposphere and lower stratosphere by subvisible cirrus clouds near the tropical tropopause, Geophys. Res. Lett., 23, 825-828, doi:10.1029/96GL00722, 1996.

Jensen, E. J., Pfister, L., and Toon, O. B.: Impact of radiative heating, wind shear, temperature variability, and microphysical processes on the structure and evolution of thin cirrus in the tropical tropopause layer, J. Geophys. Res., 116, 2156-2202, doi:10.1029/2010JD015417, 2011.

Jensen, E. J., Diskin, G., Lawson, R. P., Lance, S., Bui, T. P., Hlavka, D., McGill, M., Pfister, L., Toon, O. B., and Gao, R.: Ice nucleation and dehydration in the Tropical Tropopause Layer, P. Natl. Acad. Sci. USA, 110, 2041-2046, doi:10.1073/pnas.1217104110, 2013.

Kienast-Sjögren, E., Miltenberger, A. K., Luo, B. P., and Peter, T.: Sensitivities of Lagrangian modelling of mid-latitude cirrus 
clouds to trajectory data quality, Atmos. Chem. Phys., 15, 74297447, doi:10.5194/acp-15-7429-2015, 2015.

Kiladis, G. and Feldstein, S.: Rossby wave propagation into the tropics in two GFDL general circulation models, Clim. Dynam., 9, 245-252, 1994.

Kim, J.-E. and Alexander, M. J.: Direct impacts of waves on tropical cold point tropopause temperature, Geophys. Res. Lett., 42, 1584-1592, doi:10.1002/2014GL062737, 2015.

Koop, T., Luo, B., Tsias, A., and Peter, T.: Water activity as the determinant for homogeneous ice nucleation in aqueous solutions, Nature, 406, 611-614, doi:10.1038/35020537, 2000.

Krämer, M., Schiller, C., Afchine, A., Bauer, R., Gensch, I., Mangold, A., Schlicht, S., Spelten, N., Sitnikov, N., Borrmann, S., de Reus, M., and Spichtinger, P.: Ice supersaturations and cirrus cloud crystal numbers, Atmos. Chem. Phys., 9, 3505-3522, doi:10.5194/acp-9-3505-2009, 2009.

Kunz, A., Spelten, N., Konopka, P., Müller, R., Forbes, R. M., and Wernli, H.: Comparison of Fast In situ Stratospheric Hygrometer (FISH) measurements of water vapor in the upper troposphere and lower stratosphere (UTLS) with ECMWF (re)analysis data, Atmos. Chem. Phys., 14, 10803-10822, doi:10.5194/acp14-10803-2014, 2014.

Kärcher, B. and Burkhardt, U.: A cirrus cloud scheme for general circulation models, Q. J. Roy. Meteor. Soc., 134, 1439-1461, doi:10.1002/qj.301, 2008.

Lawson, R. P., Pilson, B., Baker, B., Mo, Q., Jensen, E., Pfister, L., and Bui, P.: Aircraft measurements of microphysical properties of subvisible cirrus in the tropical tropopause layer, Atmos. Chem. Phys., 8, 1609-1620, doi:10.5194/acp-8-1609-2008, 2008.

Liu, Y. S., Fueglistaler, S., and Haynes, P. H.: Advectioncondensation paradigm for stratospheric water vapor, J. Geophys. Res.-Atmos., 115, 2156-2202, doi:10.1029/2010JD014352, 2010.

McFarquhar, G. M., Heymsfield, A. J., Spinhirne, J., and Hart, B.: Thin and subvisual tropopause tropical cirrus: Observations and radiative impacts, J. Atmos. Sci., 57, 1841-1853, 2000.

Mioche, G., Josset, D., Gayet, J.-F., Pelon, J., Garnier, A., Minikin, A., and Schwarzenboeck, A.: Validation of the CALIPSO-CALIOP extinction coefficients from in situ observations in midlatitude cirrus clouds during the CIRCLE2 experiment, J. Geophys. Res.-Atmos., 115, 2156-2202, doi:10.1029/2009JD012376, 2010.

Morrison, H., Curry, J. A., and Khvorostyanov, V. I.: A New Double-Moment Microphysics Parameterization for Application in Cloud and Climate Models. Part I: Description, J. Atmos. Sci., 62, 1665-1677, doi:10.1175/JAS3446.1, 2005.

Muhlbauer, A., Berry, E., Comstock, J. M., and Mace, G. G.: Perturbed physics ensemble simulations of cirrus on the cloud system-resolving scale, J. Geophys. Res.-Atmos., 119, 47094735, doi:10.1002/2013JD020709, 2014.

Muhlbauer, A., Ackerman, T. P., Lawson, R. P., Xie, S., and Zhang, Y.: Evaluation of cloud-resolving model simulations of midlatitude cirrus with ARM and A-train observations, J. Geophys. Res.-Atmos., 120, 6597-6618, doi:10.1002/2014JD022570, 2015.

Murphy, D. M.: Rare temperature histories and cirrus ice number density in a parcel and a one-dimensional model, Atmos. Chem. Phys., 14, 13013-13022, doi:10.5194/acp-14-13013-2014, 2014.
Podglajen, A., Hertzog, A., Plougonven, R., and Žagar, N.: Assessment of the accuracy of (re)analyses in the equatorial lower stratosphere, J. Geophys. Res., 119, 11166-11188, doi:10.1002/2014JD021849, 2014.

Randel, W. J.: Upper Tropospheric Equatorial Waves In Ecmwf Analyses, Q. J. Roy. Meteor. Soc., 118, 365-394, doi:10.1002/qj.49711850409, 1992.

Riese, M., Ploeger, F., Rap, A., Vogel, B., Konopka, P., Dameris, M., and Forster, P.: Impact of uncertainties in atmospheric mixing on simulated UTLS composition and related radiative effects, J. Geophys. Res.-Atmos., 117, 2156-2202, doi:10.1029/2012JD017751, 2012.

Skamarock, W. C., Klemp, J. B., Dudhia, J., Gill, D. O., Barker, D. M., G., D. M., Huang, X.-Y., Wang, W., and Powers, J. G.: A description of the Advanced Research WRF Version 3., Tech. Rep., Natl. Cent. for Atmos. Res., 2008.

Spichtinger, P. and Krämer, M.: Tropical tropopause ice clouds: a dynamic approach to the mystery of low crystal numbers, Atmos. Chem. Phys., 13, 9801-9818, doi:10.5194/acp-13-98012013, 2013.

Stubenrauch, C. J., Cros, S., Guignard, A., and Lamquin, N.: A 6-year global cloud climatology from the Atmospheric InfraRed Sounder AIRS and a statistical analysis in synergy with CALIPSO and CloudSat, Atmos. Chem. Phys., 10, 7197-7214, doi:10.5194/acp-10-7197-2010, 2010.

Taylor, J. R., Randel, W. J., and Jensen, E. J.: Cirrus cloudtemperature interactions in the tropical tropopause layer: a case study, Atmos. Chem. Phys., 11, 10085-10095, doi:10.5194/acp11-10085-2011, 2011.

Thompson, G. and Eidhammer, T.: A Study of Aerosol Impacts on Clouds and Precipitation Development in a Large Winter Cyclone, J. Atmos. Sci., 71, 3636-3658, doi:10.1175/JAS-D-130305.1, 2014.

Thompson, G., Rasmussen, R., and Manning, K.: Explicit Forecasts of winter precipitation using an improved bulk microphysics scheme. Part I: Description and sensitivity analysis., Mon. Weather Rev., 132, 519-542, 2004.

Thompson, G., Field, P. R., Rasmussen, R. M., and Hall, W. D.: Explicit Forecasts of Winter Precipitation Using an Improved Bulk Microphysics Scheme. Part II: Implementation of a New Snow Parameterization, Mon. Weather Rev., 136, 5095-5115, doi:10.1175/2008MWR2387.1, 2008.

Wang, B. and Xie, X.: Low-Frequency equatorial waves in vertically shear flow. Part I: Stable waves., J. Atmos. Sci., 53, 449467, 1996.

Wang, P.-H., Minnis, P., McCormick, M. P., Kent, G. S., and Skeens, K. M.: A 6-year climatology of cloud occurrence frequency from Stratospheric Aerosol and Gas Experiment II observations (1985-1990), J. Geophys. Res., 101, 29407-29429, doi:10.1029/96JD01780, 1996.

Wang, T. and Dessler, A. E.: Analysis of cirrus in the tropical tropopause layer from CALIPSO and MLS data: A water perspective, J. Geophys. Res.-Atmos., 117, 2156-2202, doi:10.1029/2011JD016442, 2012.

Waugh, D. W. and Polvani, L. M.: Climatology of intrusions into the tropical upper troposphere, Geophys. Res. Lett., 27, 3857-3860, doi:10.1029/2000GL012250, 2000.

Wernli, H., Paulat, M., Hagen, M., and Frei, C.: Sal - a novel quality measure for the verification of quantitative pre- 
cipitation forecasts., Mon. Weather Rev., 136, 4470-4487, doi:10.1175/2008MWR2415.1, 2008.

Winker, D. M., Hunt, W. H., and McGill, M. J.: Initial performance assessment of CALIOP, Geophys. Res. Lett., 34, 19448007, doi:10.1029/2007GL030135, 2007.
Wu, L., Su, H., Jiang, J. H., and Read, W. G.: Hydration or dehydration: competing effects of upper tropospheric cloud radiation on the TTL water vapor, Atmos. Chem. Phys., 12, 7727-7735, doi:10.5194/acp-12-7727-2012, 2012. 